\title{
3D-printed Nerve Guidance Conduits Multi- functionalized with Canine Multipotent Mesenchymal Stromal Cells Promote Neuroregeneration after Sciatic Nerve Injury in Rats
}

\section{Diego Noé Rodríguez-Sánchez ( $\nabla$ diego.noe@unesp.br)}

Sao Paulo State University Julio de Mesquita Filho: Universidade Estadual Paulista Julio de Mesquita

Filho https://orcid.org/0000-0001-6524-5939

\section{Giovana Boff Araujo Pinto}

São Paulo State University

Luciana Cartarozzi

University of Campinas

Alexandre de Oliveira

University of Campinas

Ana Livia Bovolato

Sao Paulo State University Julio de Mesquita Filho: Universidade Estadual Paulista Julio de Mesquita Filho

\section{Marcio de Carvalho}

Sao Paulo State University Julio de Mesquita Filho: Universidade Estadual Paulista Julio de Mesquita Filho

Jorge Vicente da Silva

Information Thecnology Center Renato Archer

Janaina Dernowsek

Information Thecnology Center Renato Archer

Marjorie Golim

São Paulo State University

\section{Benedito Barraviera}

Sao Paulo State University Julio de Mesquita Filho: Universidade Estadual Paulista Julio de Mesquita Filho

\section{Rui Seabra Ferreira}

Sao Paulo State University Julio de Mesquita Filho: Universidade Estadual Paulista Julio de Mesquita Filho

\section{Elenice Deffune}

São Paulo State University

Matheus Bertanha 
Sao Paulo State University Julio de Mesquita Filho: Universidade Estadual Paulista Julio de Mesquita Filho

\section{Rogério Amorim}

Sao Paulo State University Julio de Mesquita Filho: Universidade Estadual Paulista Julio de Mesquita Filho

\section{Research}

Keywords: canine mesenchymal stem cells, nerve regeneration, sciatic nerve injury, cell-based therapy, tissue engineering, nerve guidance conduits, 3D printing, fibrin, scaffold

Posted Date: December 7th, 2020

DOl: https://doi.org/10.21203/rs.3.rs-117840/v1

License: (c) (i) This work is licensed under a Creative Commons Attribution 4.0 International License. Read Full License 


\section{Abstract}

Background: Nerve injuries are debilitating, leading to long-term motor deficits. Remyelination and axonal growth are supported and enhanced by growth factor and cytokines. Combination of nerve guidance conduits (NGCs) with adipose-tissue-derived multipotent mesenchymal stromal cells (AdMSCs) has been performing promising strategy for nerve regeneration.

Methods: 3D-printed polycaprolactone (PCL)-NGCs were fabricated. Wistar rats subjected to critical sciatic nerve damage (12-mm gap) were divided into sham, autograft, PCL (empty NGC), and PCL+MSC (NGC multi-functionalized with $10^{6}$ canine AdMSC embedded in heterologous fibrin biopolymer) groups. In vitro, the cells were characterized and directly stimulated with interferon-gamma to evaluate their neuroregeneration potential. In vivo, the sciatic and tibial functional indices were evaluated for 12 weeks. Gait analysis and nerve conduction velocity were analyzed after 8 and 12 weeks. Morphometric analysis was performed after 8 and 12 weeks following lesion development. Real-time PCR was performed to evaluate the neurotrophic factors BDNF, GDNF, and HGF, and the cytokines IL-6 and IL-10. Immunohistochemical analysis for the p75 ${ }^{\mathrm{NTR}}$ neurotrophic receptor, $\mathrm{S} 100$, and neurofilament was performed with the sciatic nerve.

Results: The inflammatory environment in vitro have increased the expression of neurotrophins $B D N F$, $G D N F, H G F$, and $I L-10$ in canine AdMSCs. Nerve guidance conduits multi-functionalized with canine AdMSCs embedded in HFB improved functional motor and electrophysiological recovery compared with PCL group after 12 weeks. However, the results were not significantly different than those obtained using autografts. These findings were associated with a shift in the regeneration process towards the formation of myelinated fibers. Increased immunostaining of BDNF, GDNF, and growth factor receptor $\mathrm{p} 75^{\mathrm{NTR}}$ was associated with the upregulation of BDNF, GDNF, and HGF in the spinal cord of the PCL+MSC group. A trend demonstrating higher reactivity of Schwann cells and axonal branching in the sciatic nerve was observed, and canine AdMSCs were engrafted at 30 days following repair.

Conclusions: 3D-printed NGCs multi-functionalized with canine AdMSCs embedded in heterologous fibrin biopolymer as cell scaffold exerted neuroregenerative effects. Our multimodal approach, support the trophic microenvironment, resulting in a pro-regenerative state after critical sciatic nerve injury in rats.

\section{Background}

Peripheral nervous system (PNS) injuries are debilitating, and result in long-term sensorimotor defects, leading to a negative quality of life in dogs and humans beings [1, 2]. In dogs, injuries of the brachial plexus or sciatic nerve are common [2-4]. In human, epidemiological studies showed a PNS injury incidence rate of 13.9 individuals per 100,000 habitants per year and $2-5 \%$ of patients admitted to level I trauma centers might have PNS injuries [5]. In this context, peripheral nerve injuries occurring naturally in dogs display similar features with human disease hold promise for providing predictive proof of concept in the evaluation of new therapeutics and bioengineering devices [6]. 
Complete regeneration of nerves does not occur in critical lesions with long gaps [7, 8]. The distal stump in lesions with long-gap defects does not respond to trophic signals released by the proximal stump, resulting in poor nerve regrowth [9]. This regenerative response is associated with a complex interaction between the Wallerian degeneration process, the immunological response, Schwann cells, and proregenerative molecules such as neurotrophic factors and cytokines [9]. Autografting is the current standard treatment for nerve injuries, resulting in long-gap defects [10]. However, this procedure has several disadvantages, such as additional damage to donor nerves, and insufficient revascularization [10]. These limitations have led to the development of nerve guidance conduits (NGCs) for nerve repair, that guide regenerating axons, support vascularization, increase the concentration of trophic factors, and avoid the formation of scarred tissue [11, 12].

Types of NGCs, namely, synthetic (e.g., polyglycolic acid [PGA] and polycaprolactone [PCL]) and biological (e.g., veins, arteries, or collagen), have been studied as alternatives to autografts in short-gap models. However, the functional results of such conduits were not superior to those of autografts in longgap defects [10,13-17]. Typically, conventional fabrication techniques can only result in the development of NGCs with simple architectures (e.g., straight hollow conduits) with limited choices of materials and dimensions [18]. Inferior results obtained using hollow NGCs were associated with insufficient migration of Schwann cells and lack of pro-regenerative molecules [19].

Additive manufacturing, also known as Three-dimensional (3D) printing, is a process of joining materials to make parts from 3D model data, usually layer upon layer, as opposed to subtractive and formative manufacturing methodologies $[18,20,21]$. Therefore, this robotics-based biomanufacturing approach can be used for the development of biocompatible tissue repair constructs with high flexibility and geometric freedom offering a differential advantage for medical devices production $[18,20,21], 3 D$ printing offers the possibility to control the architecture using biocompatible polymers [18, 22, 23]. NGCs manufactured via 3D printing vary in complexity and size [21-23]. The advantages of 3D printing constructs include mechanical stability, pore interconnectivity and customizability $[18,23]$. Polycaprolactone (PCL) is a thermoplastic, non-toxic, biodegradable, and hydrophobic polymer widely used as a scaffold biomaterial in vivo and can be adapted to 3D printing [11,24-27]. Nerve guidance conduits (NGCs) constructed with PCL proved to be an adequate substrate for the survival and differentiation of Schwann cells and mesenchymal stromal cells (MSCs) [27, 28].

The combination of NGCs, extracellular matrix, cells, and growth factors and their interactions could be potential tools for restoring damaged nerve tissue $[11,12]$. The efficiency of Schwann cells has been demonstrated; however, certain limitations are associated, including isolation and expansion under ex vivo conditions [29]. Due to their proliferative ability and easy accessibility, adipose-tissue-derived MSCs (AdMSCs) exhibit a translational potential [30-33]. Previous studies have demonstrated the potential of MSC to secrete powerful neurotrophic factors as well as anti-inflammatory and immunomodulatory molecules, thereby favoring nerve regeneration [30, 34-36]. 
The paracrine activity of AdMSCs is dependent on their viability and homing into the local inflammatory microenvironment [31,37]. In this study, we used a scaffold composed of heterologous fibrin biopolymer (HFB) with adhesive and sealant properties to maintain canine AdMSCs in the local of lesion and to improve their therapeutic potential [38-41]. Recent studies have shown the ability to this fibrin to adhere and support the regeneration in the spinal cord and ventral and dorsal roots injuries in experimental models [42-46]. We hypothesized that the multi-functionalization of PCL-NGCs manufactured by 3D printing with canine AdMSCs embedded in fibrin biopolymer can enhance nerve regeneration following the repair of critical nerve injury in rats.

\section{Methods}

\section{Experimental design}

Female Wistar rats (Rattus novergicus) with weights in the range of 200-300 g were used for the experimental procedures. The rats were maintained under controlled humidity, temperature, and constant light/dark cycles. All procedures were performed in accordance with the ethical principles set forth by the National Council of Animal Experimentation (CONCEA) and with the approval of the Ethics Committee in Animal Experimentation of São Paulo State University (CEUA/FMB, UNESP, protocol no. 1243-2017). The animals were divided into four groups. In the sham group $(n=5)$, the sciatic nerve was surgically exposed without any changes. The proximal and distal segments were resected, forming a gap of $12 \mathrm{~mm}$, and sutured with perineural stitches in the animals of the autograft group $(n=5)$. In the PCL group, a gap of $12 \mathrm{~mm}$ was formed with nerve resection, and an NGC empty was fixed $(n=5)$. In the PCL+MSC group, a gap of $12 \mathrm{~mm}$ was formed, and the NGC was fixed and multi-functionalized with AdMSCs embedded in HFB $(n=5)$. The sciatic functional index (SFI) and tibial functional index (TFI) were evaluated in vivo for 12 weeks after injury. Gait analysis was evaluated using the Catwalk system, and nerve conduction velocity (NCV) was measured at 8 and 12 weeks. Morphometric analysis was performed 8 and 12 weeks post-injury. To evaluate the production of neurotrophic factors at 4 weeks, brain-derived neurotrophic factor (BDNF), glial cell line-derived neurotrophic factor, hepatocyte growth factor (HGF), and the cytokines interleukin - 6 (IL-6) and interleukin - 10 (IL-10) in the spinal cord, real-time PCR (RT-qPCR) was performed nerve in both sham and PCL+MSC groups $(n=3)$. In addition, immunohistochemical analysis of the sciatic nerve for BDNF, GDNF, p75 neurotrophin receptor (p75 $\left.{ }^{\mathrm{NTR}}\right), \mathrm{S}-100$ and neurofilament were performed in both sham and PCL+MSC groups $(n=3)$.

\section{Isolation, differentiation, and characterization of canine AdMSCs}

Subcutaneous canine adipose tissue was obtained from healthy young female dogs undergoing elective surgery in accordance with a previously published protocol [47]. Adipose tissue was digested in $0.04 \%$ type $1 \mathrm{~A}$ collagenase $\left(1 \mathrm{mg} / \mathrm{mL}\right.$, Thermo Fisher Scientific, São Paulo, Brazil) for $1 \mathrm{~h}$ at $37^{\circ} \mathrm{C}$ with gentle shaking. Digested tissue was blocked, centrifuged, and filtered (BD Falcon cell strainer, $70 \mu \mathrm{m}$, San Jose, 
CA, USA). Canine AdMSCs were isolated based on their inherent property of plastic adherence in culture media containing 90\% Dulbecco's modified Eagle's medium (DMEM), 10\% fetal bovine serum (FBS), and $1 \%$ penicillin/streptomycin (100 U/mL) (all from Gibco, Grand Island, NY, USA). Cellular expansion was continued until the third passage, and the cells were cryopreserved to induce differentiation, for immunophenotypic analysis and transplantation later on.

Canine AdMSCs were tested for their ability to differentiate into of adipocyte, osteoblast, and chondrocyte lineages. Differentiation was induced in cells that underwent third passage using StemPro adipogenesis, chondrogenesis, and osteogenesis differentiation kits (Gibco, Grand Island, NY, USA) following the manufacturer's recommendations. The cells were fixed in paraformaldehyde (4\%, pH 7.34) 2 weeks after stimulation, and the evaluation of osteogenic and adipogenic differentiation were performed using histological stains, namely, Alizarin red (2\%, $\mathrm{pH} 4.2)$ and Oil red (0.5\% in isopropanol) (Sigma-Aldrich, Saint Louis, MA, USA), respectively. Three weeks after chondrogenic differentiation, the cells cultured as a micromass were fixed in 10\% formalin, embedded in paraffin, and stained with hematoxylin-eosin. Samples were analyzed and photographed under an inverted light microscope using LAS 4.0 software (DM IRB; Leica Microsystems, Wetzlar, Germany).

Canine AdMSCs were characterized by the presence of the surface marker CD90 or absence of surface markers CD45, CD34, and CD71 [48,49]. The concentration of cells in the third passage was counted and adjusted to $1 \times 10^{5}$ cells. Subsequently, the cells were incubated with primary antibody conjugates CD90PerCP (BD Pharmigen ${ }^{T M}$, San Diego, CA, USA), CD71-FITC (BD Pharmigen $\left.{ }^{T M}\right)$, CD45-PE (BD Pharmigen ${ }^{T M}$ ), and CD34-FITC (BD Pharmigen ${ }^{\mathrm{TM}}$ ). Antibodies were incubated for $30 \mathrm{~min}$ at room temperature. Cells were then washed with phosphate-buffered saline (PBS) and FACSCalibur ${ }^{\circledR}$ 4-color cytometer (Becton Dickinson Company, San Jose, CA, USA) was used to acquire and analyze the samples, standardizing a

total of $2 \times 10^{4}$ events collected per tube. Cells incubated without primary antibodies were used as controls to distinguish non-specific fluorescence. The gate on canine AdMSCs population was based on the parameters of size (forward scatter) versus cell granularity (side scatter), following the phenotypic characterization. The analyses were performed using CellQuestPro ${ }^{\circledR}$ and FlowJo ${ }^{\circledR}$ software.

\section{Stimulation of Canine Ad-MCSs with interferon-gamma}

Canine AdMSCs were activated via direct stimulation to evaluate the properties of neurotrophic and antiinflammatory molecules using a recombinant inflammatory mediator relevant to nerve injury, following a previously described protocol with minor modifications [50]. Cells were stimulated with canine interferongamma (IFN-ã) in the third passage. Triplicates were obtained with $2 \times 10^{5}$ cells $/ \mathrm{cm}^{2}$ per well in a 24-well plate (Costar ${ }^{\circledR}, T C$-treated, Corning, NY, USA). Subsequently, cells were stimulated with $0.75 \mathrm{~mL}$ basal medium containing IFN-ã ( 50 ng/mL, IFN-ã canine recombinant; Kingfisher Biotech, Saint Paul, USA) for $96 \mathrm{~h}$. At this point, the cells were collected using TRIzol reagent (Invitrogen, São Paulo, Brazil) and stored at $-80^{\circ} \mathrm{C}$ for RNA extraction and analysis of gene expression. For the control, cells were cultured in basal culture medium containing DMEM and 10\% FBS (all from Gibco). 
Gene expression of neurotrophic factors (BDNF, GDNF, and HGF) and anti-inflammatory molecules (IL-10) was quantified. Cells were lysed and homogenized with TRIzol reagent, and RNA extraction was performed using the Mini RNAeasy kit (Qiagen, São Paulo, Brazil). RNA was eluted with RNA-free water and quantified and analyzed by spectrophotometry using a NanoDrop 2000 spectrophotometer (Thermo Fischer Scientific, Wilmington, USA) for the absorbance ratios 260/280 nm and 260/230 nm. Total RNA extracted from the cells was of high quality and purity, indicating that the extraction method was efficient. cDNA was synthesized using a High-Capacity cDNA Reverse Transcription Kit (Applied Biosystems ${ }^{\mathrm{TM}}$, Thermo Fischer Scientific, Carlsbad, USA), followed by amplification using a Veriti 96 Well Thermal Cycler (Applied Biosystems ${ }^{T M}$, Thermo Fischer Scientific). The cDNA samples were cryopreserved and used as templates for PCR reactions.

The reactions were performed in triplicate, using the cDNA produced in previous steps as a template, with a PowerUp SYBR Green Master Mix (Applied Biosystems ${ }^{T M}$, Thermo Fischer Scientific Baltics, Vilnius, Lithuania), RNA-free water, and canine primers (Thermo Fisher Scientific, São Paulo, Brazil) (Additional file 1: Table S1). The samples were tested with two reference genes, glyceraldehyde-3-phosphate dehydrogenase (GAPDH) and hypoxanthine phosphoribosyltransferase (HPRT). The qPCR reaction was performed using the QuantStudio ${ }^{\text {TM }}$ 12K Flex Real-Time PCR System thermocycler (Applied Biosystems, Life Technologies, Carlsbad, CA, USA) with the following parameters: $50^{\circ} \mathrm{C}$ for $2 \mathrm{~min}, 95^{\circ} \mathrm{C}$ for $2 \mathrm{~min}$, and 45 cycles of $95^{\circ} \mathrm{C}$ for $1 \mathrm{~s}$ and $60^{\circ} \mathrm{C}$ for $30 \mathrm{~min}$. Relative quantification of expression of the genes of interest was performed using the $\Delta \Delta \mathrm{Ct}$ method [51].

\section{Fabrication and assembly of NGCs}

The NGCs were assembled from 3D-printed PCL membranes. The membranes fabrication was based on a material extrusion process called fused filament fabrication (FFF) using FAB@CTI (Renato Archer Information Technology Center - CTI, São Paulo, Brazil) an experimental 3D printing platform [52]. Previously, the filament extrusion head was adapted to different diameters and melting temperatures, which allowed the molding of a thermoplastic polymer via an orifice (open-ended die) [53]. Previous studies have evaluated the interactions between MSCs and 3D-printed PCL matrices [54]. The printing parameters were defined using FAB@CTI software (Renato Archer Information Technology Center - CTI, São Paulo, Brazil). The following parameters were set: jog speed $2,400 \mathrm{~Hz}$, deposition rate 0.07 , path speed $8.8 \mathrm{~mm} / \mathrm{s}$, path width $0.3 \mathrm{~mm}$, path height $0.3 \mathrm{~mm}$, and temperature of $80^{\circ} \mathrm{C}$. The 3D-printed membranes were sputter-coated with gold (MED 010; Balterz Union) and visualized using a scanning electron microscope (ESEM Quanta 200; Fei Company, Oregon, USA). The geometric parameters were evaluated using image analysis software (ImageJ, National Institute of Health, Bethesda). During the assembly of NGCs, the membranes were wrapped around a 1.5-mm support and sealed with controlled heating. The NGCs were sterilized by washing with a $70 \%$ ethanol solution for $10 \mathrm{~s}$, followed by washing with distilled water. After drying at room temperature, the NGCs were subjected to UV irradiation (200$280 \mathrm{~nm}$ ) for $2 \mathrm{~h}$. 


\section{Heterologous Fibrin Biopolymer (HFB) scaffold}

The HFB was kindly supplied in sufficient quantity for this study by the Center for the Study of Venoms and Venomous Animals at São Paulo State University, Brazil. The components and formula of the applied HFB are contained in its patents (registry number: BR1020140114327 and BR1020140114360). The product is distributed in three vials, stored at $-20^{\circ} \mathrm{C}$, and must be mixed and applied immediately at the site of interest [39-44].

\section{Experimental injury and repair with NGCs}

Sciatic nerve experimental injury was induced in rats under the influence of anesthesia containing isoflurane (Isoforine ${ }^{\circledR}$; Cristalia, São Paulo, Brazil) using a microsurgical microscope (DF Vasconcelos, São Paulo, Brazil). The experimental lesion consisted of a gap of $12 \mathrm{~mm}$, which was considered to be above the experimental critical level in rats [55]. In the sham group, the nerves were exposed without any modifications. In the autograft group, the proximal and distal segments were resected, inducing a gap of $12 \mathrm{~mm}$ and suturing with perineural stitches (9/0 nylon; Shalon, Brazil). In the PCL group, nerve stumps were introduced and fixed $1 \mathrm{~mm}$ into the NGC (9/0 nylon; Shalon). In the PCL+MSC group, nerve stumps were introduced and fixed $1 \mathrm{~mm}$ into the NGC (9/0 nylon; Shalon).

Thereafter, NGCs were multi-functionalized with $1 \times 10^{6}$ canine AdMSCs embedded in HFB that has been previously tested as a cell scaffold $[40,41,56]$. Fibrin polymerizes rapidly following the mixing of three components, namely, cryoprecipitated from water buffalos (Bubalus bubalis) blood, calcium chloride, and thrombin-like protein purified from South American rattlesnake (Crotalus durissus terrificus) [39, 41]. First, $10^{6}$ AdMSCs were mixed with $25 \mu \mathrm{L}$ of cryoprecipitated. The nerve guidance conduit was loaded slowly and homogeneously with a cryoprecipitated + AdMSC solution using a microsyringe ( $50 \mu \mathrm{L}, 22 \mathrm{~s}$-gauge, point style 2; Hamilton, Nevada, USA). Subsequently, a solution of $12.5 \mu \mathrm{L}$ of calcium chloride and 12.5 $\mu \mathrm{L}$ thrombin-like was administered, resulting in a final suspension with a volume of $50 \mu \mathrm{L}$. This process allowed the formation of a homogeneous cell/fibrinogen suspension into the NGC at the first step, which was coagulated after contact with thrombin $+\mathrm{CaCl}_{2}$ within the NGC. Following surgical procedures, the musculature was co-opted in layers. Rats were administered tramadol intraoperatively $(20 \mathrm{mg} / \mathrm{kg} / \mathrm{SC})$ and in the postoperative periods $(2.5 \mathrm{mg} /$ day in water for 5 days).

\section{Sciatic and tibial nerve functional indices}

Functional indices were evaluated preoperatively and weekly during the 12-week observation period in the sham, autograft, PCL, and PCL+MSC groups. The plantar surface of the hind limbs was moistened with black ink. The rats walked with a standard walk trace on a sheet of white paper where the footprints were recorded. Subsequently, the distance between the third toe and the hind limb pads (print length, PL), the first and the fifth toes (toe spread, TS), and the second and fourth toes (intermediary toe spread, ITS) 
were measured. These parameters were evaluated with the right (lesioned) and left (unlesioned) hind limbs, and the values were calculated using the following formulas described by Bain et al., 1989 [57]: sciatic functional index: -38.3 ([EPL-NPL]/NPL) + 109.5 ([ETS-NTS]/NTS) + 13.3 ([EIT-NIT]/NIT) - 8.8 (30, 31); IFP = 174.9 (EPL囚NPL/NPL) + 80.3 (ETS \NTS/NTS) - 13.4; tibial functional index: -37.2 ([EPLNPL]/NPL) + 104.4 ([ETS-NTS]/NTS) + 45.6 ([EIT- NIT]/NIT) - 8.8. Sciatic and tibial functional indices equal to -100 indicated total impairment of the sciatic and posterior tibial nerves, whereas values oscillating around 0 reflected a normal function of the three nerves. The mean \pm standard deviation was calculated with three gait cycles for each experimental group each week.

\section{Gait analysis}

Functional locomotor recovery was evaluated using the CatWalk System (Noldus, Wageningen, Netherlands). Catwalk analysis was performed preoperatively and after 8 and 12 weeks in sham, autograft, PCL, and PCL+MSC groups. The CatWalk walkway consisted of a glass roof $(100 \times 15 \times 0.6$ $\mathrm{cm})$. Rats were placed on the CatWalk walkway and allowed to walk freely. The LED light emitted from an encased fluorescent lamp was reflected along the glass plate, thereby intensifying the areas on which the front limbs and hind limbs were in contact with the glass plate. The contact areas were captured by a high-speed video camera positioned underneath the glass plate connected to a computer running Catwalk software v10.5 (Noldus). The camera was calibrated, and the signals were digitized, frame-byframe, using the PClmage-SG video card (Matrix vision $\mathrm{GmH}$, Oppenheimer, Germany) and sent to the matrix for classification. Three runs were performed and classified from each animal and the parameters were obtained for each animal at each time point. The following parameters were recorded: maximum contact area (ipsilateral (left)/contralateral (right) ratio), maximum contact intensity (ipsilateral (left)/contralateral (right) ratio), swing speed (ipsilateral (left)/contralateral (right) ratio), and swing (seconds) (swing exercised by the limbs when they are not in contact with the glass plate) and stand time (seconds).

\section{Nerve conduction velocity}

Nerve conduction velocity (NCV) was calculated preoperatively and after 8 and 12 weeks in the sham, autograft, $\mathrm{PCL}$, and PCL+MSC groups, according to a previously published protocol $[58,59]$. Under

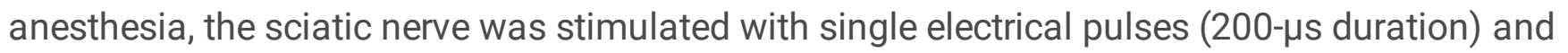
supramaximal stimulation that ensured maximal amplitude. Using needle electrodes, the sciatic nerve was percutaneously stimulated proximal to the lesion site at the level of the sciatic notch and distal to the lesion at the level of the ankle. Compound muscle action potentials (cMAP) of the plantar muscles were recorded using monopolar needles inserted into the muscle bellies and displayed with an oscilloscope (Sapphire II 4ME; Teca medelec, USA). Motor NCV was calculated by dividing the distance between stimulation sites by the average latency evoked from two sites (sciatic notch and ankle). The mean \pm standard deviation was calculated for each experimental group and at each evaluated time point. 


\section{Specimen preparation and morphometric analysis}

Nerves were harvested after 8 and 12 weeks from the sham, autograft, PCL, and PCL+MSC groups. Under general anesthesia with isofluorane (Isoforine ${ }^{\circledR}$; Cristalia, Brazil), rats were euthanized with barbiturate overdose (Thiopentax, Cristalia, São Paulo, Brazil). The vascular system was rinsed by transcardial perfusion with phosphate-buffered saline (PBS; $0.1 \mathrm{M}, \mathrm{pH} 7.4$ ). Fixation was performed in $2 \%$ glutaraldehyde and $1 \%$ paraformaldehyde in PBS $(0.2 \mathrm{M}, \mathrm{pH} 7.34)$, and nerves containing NGC were immersed in the same solution for $24 \mathrm{~h}$ at $4^{\circ} \mathrm{C}$. The sciatic nerve segment into the NGC was dissected and divided into two parts: proximal and distal. Nerves were washed with PBS (0.1 M, pH 7.4) and post-fixed for $3 \mathrm{~h}$ in 1\% osmium tetroxide solution mixed with $\mathrm{PB}(\mathrm{pH}$ 7.4). The specimens were dehydrated and embedded in glycol methacrylate resin (Leica Microsystems, Heidelberg, Germany). The blocks were trimmed, and semi-thin sections (1-2 $\mu \mathrm{m}$ ) were obtained with an ultramicrotome (Leica RM 2265; Leica Microsystems CMS), which were stained with toluidine blue (0.25\%). Morphometric analysis was performed by sampling at least $30 \%$ of the cross-section of each nerve using a bright-field microscope (Leica DM 4000 B-M; Leica Microsystems CMS) [60]. The analysis was performed with two sampled fields from each nerve (magnification of 100x) using Adobe Photoshop CC 2019. Morphometric parameters evaluated included myelinated axon diameter, myelinated fiber diameter, myelin thickness

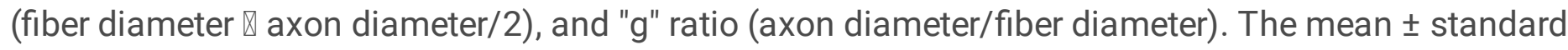
deviation was calculated for each experimental group and at each evaluated time point.

\section{Immunohistochemical study of sciatic nerve and RT-qPCR analyses of spinal cord samples}

Immunohistochemical analysis (S-100, neurofilament, BDNF, GDNF, and $\mathrm{p} 75^{\mathrm{NTR}}$ ) of sciatic nerve samples and qPCR of the spinal cord samples (BDNF, GDNF, HGF, IL-6, and IL-10) were performed for the sham and PCL+MSC ( $n=3)$ groups after 4 weeks. Rats were euthanized with barbiturate overdose (Thiopentax; Cristália). Fresh spinal cord tissue ipsilateral to the lesion was harvested, frozen in liquid nitrogen, and stored at $-80^{\circ} \mathrm{C}$. Fixation was performed in $4 \%$ paraformaldehyde in $\mathrm{PB}(0.1 \mathrm{M}, \mathrm{pH} 7.34)$, and the regenerated nerve was dissected and immersed in the same solution for $12 \mathrm{~h}$ at $4^{\circ} \mathrm{C}$. Specimens were immersed in ascending order $10 \%, 20 \%$, and $30 \%$ of the sucrose solutions $(0.1 \mathrm{M} \mathrm{PB}, \mathrm{pH} 7.4)$ for $12 \mathrm{~h}$, mixed with Tissue-Tek OCT (Sakura Finetek, Torrance, USA), and frozen at $-80^{\circ} \mathrm{C}$.

Longitudinal cryostat sections $(12 \mu \mathrm{m})$ of the sciatic nerves were acclimatized, washed, and incubated in $3 \%$ bovine serum albumin solution or $3 \%$ donkey serum in $\mathrm{PB}(0.1 \mathrm{M}, \mathrm{pH} 7.4)$ for $1 \mathrm{~h}$, followed by incubation in a moist chamber with primary antibodies against S100, neurofilament H (NF), BDNF, GDNF, and $\mathrm{p} 75^{\mathrm{NTR}}$ for $4 \mathrm{~h}$ (Additional file 2: Table S2). After rinsing with PB, the sections were incubated with Alexa Fluor 488, Alexa Fluor 546, or CY2-conjugated secondary antiserum for $45 \mathrm{~min}$ at room temperature. The sections were then mounted in a mixture of glycerol/PB (3:1) for quantitative measurements or glycerol/DAPI for qualitative analysis. Representative images were obtained using a fluorescence microscope (BX51; Olympus Corporation, Tokyo, Japan) equipped with a camera (DP 72; 
Olympus Corporation). Four images of each sample were imported for the determination of the integrated pixel density that represented the intensity of labeling using ImageJ software (version 1.33u, National Institutes of Health, USA), according to a previously published protocol $[61,62]$. The mean intensity \pm standard deviation was calculated for each group.

For RT-qPCR, the spinal cord was finely pricked and homogenized in TRIzol reagent (TRIzol ${ }^{\mathrm{TM}}$, Invitrogen ${ }^{\mathrm{TM}}$ ) and chloroform. The samples were vigorously shaken for $30 \mathrm{~s}$ using a Precellys Lysing Kit ${ }^{\circledR}$ (Uniscience, São Paulo, Brazil) with a Precellys 24 tissue homogenizer (Bertin Technologies SAS, Montigny-leBretonneuz, France). Total RNA was extracted, quantified, and reverse-transcribed to cDNA, which was amplified as described previously in the RT-qPCR assay procedure performed with cells. Assays analyzing the levels of BDNF, GDNF, HGF, IL-10, and IL- 6 were performed (all from Thermo Fisher Scientific, São Paulo, Brazil) (Additional file 3: Table S3). Samples were tested with two reference genes, $\beta 2-$ microglobulin and HPRT. The qPCR reaction was performed using the QuantStudio ${ }^{\mathrm{T}}{ }^{\mathrm{M}} 12 \mathrm{~K}$ Flex Real-Time PCR System thermocycler (Applied Biosystems ${ }^{\mathrm{TM}}{ }^{\mathrm{M}}$, Thermo Fischer Scientific) with the following parameters: $50^{\circ} \mathrm{C}$ for $2 \mathrm{~min}, 95^{\circ} \mathrm{C}$ for $2 \mathrm{~min}$, and 45 cycles of $95^{\circ} \mathrm{C}$ for $1 \mathrm{~s}$ and $60^{\circ} \mathrm{C}$ for $30 \mathrm{~min}$. Relative quantification of expression of the genes of interest was performed using the $\Delta \Delta \mathrm{Ct}$ method [51].

\section{Statistical analysis}

Variables, namely, sciatic and tibial functional indices, Catwalk analysis, and NCV were assessed for normality with statistical tests (Shapiro-Wilk or Kolmogorov-Smirnov), descriptive statistics, and graphic analyses (QQ plot). An analysis of variance test (two-way ANOVA, multiple comparisons) was performed followed by Tukey's test to verify the differences in the means of the variables between each group and the time of the experiment. Other variables (integrated pixel density and relative quantification) were assessed for normality using statistical tests (Shapiro-Wilk), descriptive statistics, and graphic analysis. For parametric data, the t-test was performed with unpaired samples. For non-parametric data, the Mann-Whitney test was performed for unpaired samples. The level of significance between the groups was set at $p<0.05$. The differences were denoted by a single asterisk $(p<0.033)$, two asterisks ( $p$ $<0.002)$, or three asterisks $(p<0.001)$ (GraphPad Prism version 8 for Mac, San Diego, CA, USA).

\section{Results}

\section{Canine AdMSC showed mesenchymal fate and differentiation potential}

Following isolation, AdMSCs demonstrated a homogeneous appearance and fusiform morphology during the first week after passage zero and reached $80 \%$ confluence and formed a monolayer in 2 weeks. Multipotentiality was detected in vitro via tri-lineage differentiation into adipocytes, osteoblasts, and chondrocytes. Alizarin red staining demonstrated the formation of an extracellular calcium matrix after 21 days. Oil Red staining confirmed the presence of intracytoplasmic lipid deposits after 14 days. 
Staining with toluidine blue demonstrated the deposition of the extracellular matrix after 21 days (Additional file 4: Figure S1). Immunophenotypic analysis of AdMSCs by flow cytometry confirmed the positive expression of CD 90 (Thy-1) and the absence of expression of hematopoietic and endothelial antigens CD45 and CD34 (transmembrane glycoproteins) and CD71 (transferrin receptor) (Additional file 4: Figure S1).

\section{Canine AdMSCs enhanced their trophic and anti- inflammatory potential after in vitro stimulation}

Gene expression of neurotrophic factors BDNF, GDNF, and HGF in AdMSCs was higher following stimulation with IFN-ã (BDNF $3.94 \pm 0.55$, GDNF $6.7 \pm 0.59$, and HGF $2.5 \pm 0.36$ ) than in unstimulated AdMSCs (BDNF 1.02 \pm 0.12 , GDNF $1.03 \pm 0.23$, and HGF $0.97 \pm 0.60$ ) (BDNF $p=0.02$; GDNF $p<0.001$, and HGF $p=0.01)$. The expression of cytokine IL-10 was significantly higher in AdMSCs following stimulation with IFN-ã $(2.66 \pm 0.36)$ than in unstimulated AdMSCs $(0.93 \pm 0.21)(p=0.07)($ Figure 1$)$.

\section{Ultrastructural analysis of 3D-printed NGCs}

The NGCs were manufactured by 3D printing with PCL membranes using the FFF technique. PCL filaments (diameter of $396 \pm 74 \mu \mathrm{m}$ ) were continuously deposited in a square geometry along the vertical direction for the first layer and the lateral direction for the second layer, resulting in the formation of a bilayer membrane with a thickness of $386 \pm 41 \mu \mathrm{m}$, and an area of $225 \mathrm{~mm}^{2}$ (Figure 2A-D). The air gaps between the filaments (areas without polymer) formed pores with a height of $312 \pm 58 \mu \mathrm{m}$ and a length of $300 \pm 51 \mu \mathrm{m}$, as depicted in Figure $2 \mathrm{E}-\mathrm{I}$. The membranes were rolled and sealed with controlled heating (Figure 2G). Smooth architecture was observed on the outer surface (Figure 2H).

\section{NGCs multi-functionalized showed positive functional motor recovery}

After 9 weeks, SFI analysis showed no significant differences between the autograft (SFI -60.19) and $P C L+M S C$ groups $(\mathrm{SFI},-67.06)(p>0.05)$. However, significant differences were observed between the autograft (SFI, -60.19) and PCL groups (SFI, -74.98) $(p=0.02)$. After 11 weeks, significant differences were observed comparing the autograft (SFI, -52.58) group with the PCL+MSC (TFI, -67.30) $(p=0.02)$ and PCL (SFI, -77.39) groups $(p<0.001)$. Significant differences were observed upon comparison of the results of the autograft (SFI, -50.40$)$ group with those of PCL+MSC (SFI, 65.12) $(p=0.03)$ and PCL (SFI, $-80.81)$ groups $(p<0.001)$ after 12 weeks. However, after 12 weeks, the analysis demonstrated superior results with the $P C L+M S C$ group $(S F I, 65.12)$ than those in the PCL $(S F I-80.81)$ group $(p<0.02)$. Thus, the autograft and PCL+MSC groups showed better functional motor recovery than the PCL group (Figure $3)$. 
Regarding TFI evaluation, no significant differences were observed from TFI analysis performed after 11 weeks between the autograft (TFI, -60.25) and the PCL+MSC groups (TFI, -75.98) ( $p>0.05)$ (Figure 3). In addition, the autograft group demonstrated better results (TFI, -64.25) than those in the PCL group (TFI, -82.81) $(p=0.004)$. Similarly, after 12 weeks, no significant differences were observed between the autograft (TFI, -60.34) and PCL+MSC groups (SFI, -72.69) $(p>0.05)$ (Figure 3). However, the autograft group (TFI, -60.34) was superior to that of the PCL $(T F I,-82.04)$ group $(p<0.001)$. The PCL+MSC group demonstrated superior functional motor recovery compared to the PCL group.

After 8 and 12 weeks during gait analysis by Catwalk, the sham group demonstrated an improved maximum contact area in comparison with the contact area demonstrated by the autograft, PCL, and $P C L+M S C$ groups $(p<0.001)$. The autograft group showed better values after 8 weeks than those in the PCL $(p=0.03)$ and PCL+MSC $(p=0.02)$ groups (Figure $4 A)$.

After 8 and 12 weeks, no significant differences were observed in the maximum contact intensity between the autograft and PCL+MSC groups $(p>0.05)$. However, the autograft group demonstrated superior results to that of the PCL group ( $p=0.03)$. After 12 weeks, maximum contact intensity was significantly higher in the PCL+MSC group than in the PCL group $(p=0.04)$ (Figure 4B).

After 8 and 12 weeks, no significant differences were observed in the swing speed between the autograft and PCL+MSC groups $(p>0.05)$. After 8 weeks, the autograft group demonstrated superior results to that of the PCL group $(p=0.02)$ (Figure $4 C)$.

After 8 and 12 weeks, no significant differences were observed in the swing values of the sham group when compared with the autograft and PCL+MSC groups $(p>0.01)$. However, after 8 weeks, the swing values of the sham group were superior to that of the PCL group $(p=0.01)$ (Figure 4D).

After 8 and 12 weeks, no significant differences were observed during the analysis of spontaneous locomotion after 8 weeks with respect to the stand time (s) among the sham, autograft, and PCL+MSC groups $(p>0.05)$. However, the sham group demonstrated a better stand than the PCL group $(p=0.019)$. After 12 weeks, the sham group demonstrated an improved stand compared with the autograft $(p=$ 0.014), PCL ( $p=0.006)$, and PCL+MSC $(p=0.004)$ groups (Figure 4E).

\section{NGCs multi-functionalized showed electrophysiological recovery}

After 8 weeks, no significant differences were observed in the conduction velocity of regenerated nerves among the sham $(42.35 \mathrm{~m} / \mathrm{s})$, autograft $(47.99 \mathrm{~m} / \mathrm{s}), P C L(28.02 \mathrm{~m} / \mathrm{s})$, and PCL+MSC $(26.98 \mathrm{~m} / \mathrm{s})$ groups ( $p>0.05)$. After 12 weeks, no significant differences in the NCV were observed among the sham $(75.08 \mathrm{~m} / \mathrm{s})$, autograft $(55.96 \mathrm{~m} / \mathrm{s})$, and PCL+MSC $(47.37 \mathrm{~m} / \mathrm{s})$ groups $(p>0.05)$. However, the NCV was significantly reduced in the PCL group $(25.50 \mathrm{~m} / \mathrm{s})(p=0.001)$. No significant differences were observed 
among the autograft, PCL+MSC, and PCL groups after the twelfth week $(p>0.05)$. These findings demonstrate an increase in NCV in the autograft and PCL+MSC groups, as shown in Figure 4F.

\section{Morphometric analysis of regenerated nerves}

Myelin thickness measures with superior percentages after 8 weeks are as follows: sham (myelin sheath thickness 1.2 to $1.7 \mu \mathrm{m}$, mean $1.54 \pm 0.01$ ), autograft (myelin sheath thickness 0.4 to $0.7 \mu \mathrm{m}$, mean 0.71 \pm 0.01 ), PCL (myelin sheath thickness 0.2 to $0.5 \mu \mathrm{m}$, mean $0.43 \pm 0.01$ ), and PCL+MSC (myelin sheath thickness 0.3 to $0.6 \mu \mathrm{m}$, mean $0.50 \pm 0.01$ ) (Figure 5A-D). After 12 weeks, the myelin thickness measures were: sham (myelin sheath thickness 1.1 to $1.5 \mu \mathrm{m}$, mean $1.35 \pm 0.01$ ), autograft (myelin sheath thickness 0.6 to $1.0 \mu \mathrm{m}$, mean 1.22 \pm 0.01 ), PCL (myelin sheath thickness 0.4 to $0.7 \mu \mathrm{m}$, mean $0.59 \pm$ 0.01 ), and PCL+MSC (myelin sheath thickness 0.4 to $0.7 \mu \mathrm{m}$, mean $0.63 \pm 0.01$ ) as showed in the Figure $5 \mathrm{E}-\mathrm{H}$. Myelinization was observed in GPCL + MSCc close to GA in 12 weeks (Figure 5I-L).

Measures of the " $g$ " ratio with superior percentages after 8 weeks are as follows: sham ( 0.6 to $0.65 \mu \mathrm{m}$, mean $0.58 \pm 0.01)$, autograft $(0.65$ to $0.7 \mu \mathrm{m}$, mean $0.60 \pm 0.01)$, PCL $(0.75$ to $0.80 \mu \mathrm{m}$, mean $0.70 \pm$ $0.01)$, and PCL+MSC ( 0.65 to $0.75 \mu \mathrm{m}$, mean $0.63 \pm 0.01$ ) (Figure 6A-D). After 12 weeks, they were: sham ( 0.65 to $0.70 \mu \mathrm{m}$, mean $0.60 \pm 0.01$ ), autograft ( 0.60 to $0.65 \mu \mathrm{m}$, mean $0.57 \pm 0.01), P C L$ ( 0.75 to $0.8 \mu \mathrm{m}$, mean $0.68 \pm 0.01)$, and PCL+MSC ( 0.6 to $0.7 \mu \mathrm{m}$, mean $0.62 \pm 0.01)$. The correlation between the " $\mathrm{g}$ " ratio and myelinated axon diameter showed a shift towards a higher number of axons exhibiting close to normal myelination in the autograft and PCL+MSC groups after 12 weeks, as shown in Figure $6 \mathrm{E}-\mathrm{H}$.

Myelinated fiber diameter and myelinated axon diameter values with greater percentages were improved in the autograft group compared to the PCL and PCL+MSC groups after 8 and 12 weeks, respectively. Similar values in the frequency distribution of myelinated fiber diameter and myelinated axon diameter were observed for the PCL and PCL+MSC groups after 8 and 12 weeks (Additional file 5: Figure S2 and Additional file 6: Figure S3).

\section{NGCs multi-functionalized enhanced p75 ${ }^{\mathrm{NTR}}$ expression and preservation of Schwann cell reactivity}

Immunoreactivities of p75 ${ }^{\mathrm{NTR}}$, Schwann cells (S-100 expression), and neurofilament were evaluated in response to sciatic nerve regeneration 30 days after lesion formation in both sham and PCL+MSC groups. Immunoreactivity of the p $75^{\mathrm{NTR}}$ receptor was higher in the PCL+MSC group $\left(5.1 \times 10^{7} \pm 0.37 \times\right.$ $\left.10^{7}\right)$ than in the sham group $\left(3.5 \times 10^{7} \pm 0.83 \times 10^{7}\right)(p=0.03)$ (Figure 7A-C). No significant differences in the immunoreactivity of S-100 were observed between the sham $\left(5.3 \times 10^{7} \pm 0.14 \times 10^{7}\right)$ and PCL+MSC groups $\left(3.9 \times 10^{7} \pm 0.55 \times 10^{7}\right)(p<0.05)$ (Figure 7D-F). The reactivity of Schwann cells was preserved (Figure 7B). The immunoreactivity of NF was superior in the sham group $\left(10.7 \times 10^{7} \pm 0.07 \times 10^{7}\right)$ than in the PCL+MSC group $\left(8.3 \times 10^{7} \pm 0.1 \times 10^{8}\right)(p=0.001)$ (Figure 7G-I). 


\section{NGCs multi-functionalized stimulated expression of neurotrophic factors}

Immunoreactivity against BDNF and GDNF was characterized in regenerating nerves obtained inside the NGC in the sham group and PCL+MSC group 30 days after the lesion. The positive expression of BDNF and GDNF is shown in Figures 8A and 9A. An increase in the intensity of the immunostaining for BDNF and GDNF was observed from the proximal region of the nerve in the PCL+MSC group compared with the sham group. The intensity was stronger in the proximal region, indicating that the PCL biomaterial functionalized with MSCs positively co-stimulated the production of neurotrophins BDNF and GDNF.

\section{Canine AdMSCs engrafted after nerve repair}

Serial histological sections were obtained 30 days following nerve repair with NGC multi-functionalized for detection of the labeled cells. Canine AdMSCs labeled with qdot655 were observed inside the NGC, in the proximal stump, confirming the survival of these cells for at least 4 weeks in vivo (Figure 8A and 9A). However, cells were not observed in the distal stumps or in regions not located in the proximity of NGC, indicating that the cells were possibly retained around the application site. In addition, the labeled cells showed co-localization with the regions that demonstrated positive immunostaining for BDNF and GDNF (Figure $8 \mathrm{~A}$ and $9 \mathrm{~A}$ ).

\section{NGCs multi-functionalized enhanced upregulation of the expression of BDNF, GDNF, and HGF in the spinal cord}

Gene expression of the neurotrophins BDNF, GDNF, and HGF was evaluated 30 days after nerve repair in both sham and PCL+MSC groups. The expression of $B D N F$ was significantly higher in the PCL+MSC group $(1.53 \pm 0.11)$ than in the sham group $(1.00 \pm 0.05)(p=0.006)$. The expression of GDNF was significantly higher in the PCL+MSC group $(1.35 \pm 0.09)$ than in the sham group $(1.01 \pm 0.09)(p=0.04)$. The expression of $H G F$ was significantly higher in the PCL+MSC group (1.74 \pm 0.25$)$ than in the sham group (1.02 \pm 0.12$)(p=0.04)$, as shown in Figure 10A-C. No significant differences in $I L-10$ expression were observed in the PCL+MSC group $(1.01 \pm 0.10)$ when compared with the sham group $(0.69 \pm 0.17)(p$ $>0.05)$. No significant differences in $I L-6$ expression were observed in the PCL+MSC group $(0.30 \pm 0.03)$ when compared with the sham group $(0.90 \pm 0.36)(p>0.05)$ (Figure 10D and $E)$.

\section{Discussion}

A tissue engineering approach that integrates NGCs, cells, and growth factors mimicking native tissues shows promise for restoring the damage in nervous tissue [11, 12, 63-66]. Exogenous application of growth-promoting for nerve regeneration might have limited applications, owing to their short biological half-life and high cost $[64,65,66]$. To overcome these limitations, studies indicated that AdMSCs secrete 
a complex mix of factors that are capable of promoting myelination, regenerating nerve fibers, exerting neuroprotective effects, stimulating angiogenesis, and modulating the inflammatory environment [3436]. Although the criteria are not fully defined for canine AdMSC characterization, the cells used in this study exhibited a comparable in vitro profile in line with previously published studies [31, 48, 49,63]. The neuroprotective effects of MSCs are primarily associated with the production of BDNF, GDNF, nerve growth factor (NGF), insulin-like growth factor (IGF), and HGF [30, 34, 35, 67-70]. Angiogenesis is associated with angiopoietin factors such as angiopoietin-1, basic fibroblast growth factor (bFGF), and vascular endothelial growth factor (VEGF) $[30,68,71]$. It is also influenced by immunoregulatory mechanisms associated with interleukin 10 (IL-10), prostaglandin E2 (PGE2), indoleamine 2,3dioxygenase (IDO), HGF, and transforming growth factor-beta (TGF- $\rightarrow$ ). [36, 72-74]. Here, we evaluated the neurogenerative capacity of NGCs fabricated by 3D printing and multi-functionalized with canine AdMSCs using HFB as cells scaffold to restore the damage caused by critical sciatic nerve injury in rats.

The inflammatory environment during Wallerian degeneration is indispensable for axonal regeneration and is characterized by a significant production of tumor necrosis factor alpha (TNF- - ) and IFN- $₫$ by Schwann cells and fibroblasts during the first 14 days following injury. This leads to the recruitment of inflammatory cells [75-78]. These infiltrated immune cells lead to a rapid clearance of myelin and facilitate nerve regeneration [79]. In this study, canine AdMSCs demonstrated constitutive expression of $B D N F, G D N F, H G F$, and $I L-10$. Furthermore, direct stimulation with IFN- $₫$ resulted in the upregulation of the expression of $B D N F, G D N F, H G F$, and $I L-10$. Neurotrophic factors BDNF and GDNF are powerful molecules that influence nerve-muscle synapsis, neuronal survival, proliferation of Schwann cells, and axonal regeneration [80, 81]. HGF is a potent angiogenic and anti-inflammatory factor with antioxidant functions and is capable of reducing glial scarring and acting synergistically with neurotrophic factors $[72,81,82]$. $\mathrm{IL}-10$ is a cytokine involved in the restoration of tissues via the regulation of inflammatory responses, extracellular matrix production, fibroblast functions, and angiogenesis [83, 84]. Studies have shown that IFN- $\gamma$ is a key player in activating the immunomodulatory function of murine and human MSCs through the production of several factors, including HGF and IL-10, which is consistent with the results of our study $[85,86]$. More importantly, through inflammation enriched with pro-inflammatory cytokines such as IFN- $y$, MSCs could be activated or primed, and the upregulation of major histocompatibility complex class I (MHC-I) can lead to improved survival [37].

Versatile NGCs should demonstrate biocompatibility along with the modulation of the cellular environment that permits cell adhesion, axonal branching, and revascularization [11]. PCL polymer has been used for the fabrication of hollow NGCs via conventional manufacturing methods, showing positive regeneration in rats $[27,28,87]$. Rapid prototyping methods such as FFF 3D printing for NGC fabrication enables the control of porosity, architecture, and reproducibility [20]. Herein, 3D-printed NGCs showed characteristics such as mechanical strength, macroporosity, and adequate geometry, in addition to biocompatibility. The fabrication of NGC with a customized architecture has been demonstrated using 3D-printing technology with a PCL polymer in few studies $[22,88]$. 
Long-gap sciatic lesions in rats (such as a 10-mm gap) are considered critical, with only $10 \%$ axons effectively regenerating into the NGC $[11,55]$. In our study, NGCs multi-functionalized showed positive results for functional motor recovery. After 8 weeks, the autograft group showed better results, following the PCL + MSC group. In addition, Catwalk analysis demonstrated an increase in the duration of the support phase (stand time), contact intensity, swing time, and velocity after 8 weeks in the PCL + MSC group compared with the PCL group. Previous studies have demonstrated functional motor recovery after a combination of allogenic MSCs and PCL NGCs were implanted in short gaps with length of 3-10 mm $[26,89,90]$. In contrast, allogeneic Schwann cells, MSCs, and polylactic acid (PLA) NGCs demonstrated functional recovery after 8 weeks with gaps of $15 \mathrm{~mm}$. However, the SFI was lower than that observed in our study [91]. Using the 3D printing approach, NGCs were customized using composite material to be implanted in a short gap of $4 \mathrm{~mm}$ in mice. However, only the sensitive function of the nerve was evaluated compared to our study [23]. In our study, our critical lesion level reflects a better clinical setting without endogenous regeneration influence. Moreover, retraction of stumps and contractures in the limbs could negatively influence functional recovery $[11,55]$.

Electrophysiological and histological evaluations are complementary techniques used for the examination of nerve regeneration. In our study, the PCL + MSC and autograft groups showed better results in NCV after 12 weeks, indicating the presence of myelinated axons. In addition, the morphometric analysis demonstrated improvements in myelin thickness in the PCL + MSC group compared with the PCL group after 8 and 12 weeks. The correlation between the " $g$ " ratio and myelinated axon diameter showed a shift towards a higher number of axons with presence of myelination after 12 weeks. Previous studies have shown improvements in the histological parameters of short-gap defects after a combination of MSCs and PCL implanted in gaps of 5-10 mm [26, 89, 90]. In long-gap defects, recovery of NCV and the presence of the highest number of myelinated axons were observed with allogeneic MSCs plus PLA-NGC after 6 weeks [92]. However, the NCV obtained in that study was lower (about $40 \mathrm{~m} / \mathrm{s}$ ) than that observed in our study [92]. Other studies have demonstrated NCV and morphometric recovery after 8 and 12 weeks following the use of MSCs and Schwann cells applied in a PLA-NGC or an acellular nerve allograft. Despite positive functional recovery, the NCVs ( 12.45 and $17 \mathrm{~m} / \mathrm{s}$, respectively) were slower than those of the PCL + MSC group observed in our study $(47.37 \mathrm{~m} / \mathrm{s})[91,93]$.

Nerve regeneration is strongly influenced by a pro-regenerative microenvironment [80]. Neurotrophins act selectively in high-affinity tropomyosin receptor kinases (trk) and low-affinity receptors p $75^{\mathrm{NTR}}$, and are expressed in Schwann cells and growth cones in regenerating nerves [9, 80, 94]. Immunolabeling results indicated a positive expression of BDNF and GDNF in association with $\mathrm{p} 75^{\mathrm{NTR}}$ in the PCL + MSC group after 30 days. Our results are comparable to those observed in previous studies in which nerve regeneration was frequently associated with the production of BDNF and GDNF during the first few weeks after MSC transplantation [34, 35, 68, 70, 74, 95]. BDNF and GDNF activate several in vivo and in vitro pathways associated with nerve regeneration, formation of nerve-muscle synapses, neuronal survival and proliferation, and survival of Schwann cells $[80,94]$. Activation of the BDNF/p $75^{\mathrm{NTR}}$ pathway instead of $\mathrm{BDNF} / \mathrm{trkB}$ plays an important role in the activation and differentiation of Schwann cells as well as in 
myelination $[80,94,96]$. Previous studies conducted with polymeric NGC (6 and $10 \mathrm{~mm}$ gaps) and allogeneic MSCs demonstrated the proliferation of Schwann cells and increased expression of neurotrophic receptors after 2 and 8 weeks, respectively $[89,97]$.

Schwann cells are crucial for axonal branching and myelin production $[9,80]$. The reactivity of Schwann cells and the organization of the cytoskeleton were evaluated using S-100 and neurofilament markers. Reactivity of S-100 was increased 30 days after nerve repair with NGC plus MSCs. NF immunostaining showed values that were close to those of the sham group. Previous studies observed S-100 expression in rats treated with allogeneic and xenogeneic MSC-TA after nerve injury $[63,97,98]$. Co-expression of S100 and neurotrophin receptors ( $\mathrm{p} 75^{\mathrm{NTR}}$ and trks) was detected in axonotmesis or neurotmesis experiments after MSC transplantation in rats $[89,97]$.

Paracrine and regenerative effects depend on AdMSC engraftment $[31,37,73]$ In our study, AdMSCs embedded in HFB survived for 30 days after transplantation into the NGC and were co-localized with BDNF and GDNF. Similarly, human AdMSCs transplanted after root avulsion in rats increased neuronal survival mediated by BDNF, GDNF, and HGF. Human MSCs were able to engraft and survive in the lesion area for at least 14 days [74]. The results of another study demonstrated the co-expression of BDNF and allogeneic MSCs positive for green fluorescent protein (GFP) after 60 days, indicating the continuous activation of these cells [25]. The main mechanism of HFB is the adhesion ability allowing support and viability of the cells for several weeks [39-44]. In our study, the application of HFB acted synergistically with the MSCs for enhancing pro-regenerative effects and, thereby contributing to nerve regeneration. As showed by immunofluorescence, canine AdMSC in co-localization with the BDNF, GDNF and p75 ${ }^{\mathrm{NTR}}$ indicates that the persistence of viable cells into the the microenvironment of lesion was crucial for the neurotrophic factor maintenance released by the cells. Previous studies showed that the use of HFB for reimplantation of ventral nerve roots lesioned or end-to-end nerve cooptation, proved cell support capacity, adhesion for axonal regeneration and neuroprotection [40-46].

Degeneration, loss of inhibitory and excitatory synapses, formation of glial scarring, and excitotoxicity are observed in neuronal bodies following peripheral nerve injury $[99,100]$. Regulation of several genes related to cell survival and axonal growth indicates changes in the pro-regenerative status of motor neurons [99]. Here, the upregulation of the expression of $B D N F, G D N F$, and $H G F$ was detected after 30 days in the PCL + MSC group, indicating a pro-regenerative response in the ventral horn of the spinal cord. In a ventral root injury model, MSC transplantation increased BDNF expression 2 weeks after injury [95]. The results of previous studies did not demonstrate the expression of neurotrophic factors in spinal cord lesions following MSC transplantation in rats or humans [100-102]. We assumed that the paracrine production of pro-regenerative factors by MSCs might result in the formation of a gradient of molecules secreted throughout peripheral nerves and influence the spinal cord to contribute to nerve regeneration.

\section{Conclusion}


The tissue engineering approach for nerve regeneration based on 3D-printed NGCs multi-functionalized with canine AdMSCs embedded in HFB showed positive functional and electrophysiological locomotor recovery after 8 and 12 weeks following critical experimental injury. In addition, it shifted to a proregenerative profile mediated by neurotrophic factors during the first 4 weeks in the microenvironment of nerves and the spinal cord, thereby improving functional recovery. Although combinatorial approaches for the treatment of PNI injuries are highly desirable, further studies are necessary to overcome the autograft technique analyzing several geometric parameters with 3D printing, as well as direct priming of MSCs and neurotrophic factors to enhance nerve regeneration.

\section{Abbreviations}

PNS: Peripheral nervous system; NGC: nerve guidance conduits; PGA: polyglycolic acid; PCL: polycaprolactone; 3D: Tridimensional; MSC: mesenchymal stromal cells; AdMSC: mesenchymal stromal cells derived from adipose tissue; HFB: heterologous fibrin biopolymer; Sham: Sham group; PCL+MSC: polycaprolactone nerve guidance channel plus canine AdMSC; SFI: Sciatic functional index; TFI: tibial functional index; NCV: Nerve conduction velocity; RT-qPCR: real time PCR; DMEM: Dulbecco's modified Eagle's medium; FBS: fetal bovine serum; IFN-ã: interferon gamma; RNA: ribonucleic acid; cDNA: complementary DNA; BDNF: brain-derived neurotrophic factor; GDNF: glial cell-derived neurotrophic factor; HGF: hepatocyte growth factor; IL-10: interleukin 10; GAPDH: glyceraldehyde-3-phosphate dehydrogenase; HPRT: hypoxanthine phosphoribosyltransferase; FFF: fused filament fabrication; cMAP: compound muscle action potentials; NF: neurofilament H; $75^{\mathrm{NTR}}$ : $\mathrm{p} 75$ neurotrophin receptor; $\mathrm{CY}$ : cyanine; PB: phosphate buffer; S100: calcium binding protein; NGF: nerve growth factor; IGF: insulin-like growth factor; TGF: transforming growth factor; bFGF: basic fibroblast growth factor; VEGF: vascular endothelial growth factor; IL-10: interleukin 10; IDO: indoleamine 2,3-dioxygenase; TGF-â: transforming growth factor beta; TNF-á: tumor necrosis factor alfa; MHC-I: major histocompatibility complex class I; GelMA: gelatin methacryloyl; PEGDA: poly(ethylene glycol) diacrylate; trk: high affınity tropomyosin receptor kinases; GFP: green fluorescent protein

\section{Declarations}

\section{Acknowledgments}

We would like to thank the Experimental Research Unit of Botucatu Medical School (UNIPEX/ FMB) and Cell Engineering Laboratory (Blood transfusion center/FMB/UNESP) for infrastructural and technical support. We are grateful to the Nerve Regeneration Laboratory (LRN) of the University of Campinas for technical support and collaboration and to the Renato Archer CTI for support in 3D printing.

\section{Authors' contributions}


Diego Noé Rodríguez-Sánchez: contributed to the conceptualization and design of the research project, collection and assembly of data, data analysis and interpretation, and manuscript writing. Giovana Boff Araujo Pinto: contributed to the collection and interpretation of the data, and manuscript writing. Luciana Cartarozzi: contributed to the collection of the data. Alexandre de Oliveira: contributed in the conceptualization, methodology and interpretation of the data. Ana Livia Bovolato: contributed to the collection of the data. Marcio de Carvalho: contributed to the performing and analysis of the RT-qPCR data. Jorge Vicente da Silva and Janaina Dernowsek contributed to the modeling and NGC-3D printing. Marjorie Golim: contributed to the flow cytometry analysis. Rui Seabra Junior and Benedito Barraviera produced and provided HFB. Elenice Deffune: contributed to the conceptualization and interpretation of the data. Matheus Bertanha: contributed to the conceptualization, interpretation of the data and resources. Rogério Amorim: contributed to the conception, design and administration of the research project, data analysis and manuscript writing. All authors have read and approved the final manuscript.

\section{Funding}

The authors are thankful to the São Paulo Research Foundation (FAPESP) for providing financial support (2016/14364-2).

\section{Availability of data and materials}

The datasets used and/or analyzed during the current study are available from the corresponding author upon request.

\section{Ethics approval and consent to participate}

All procedures were performed with the approval of the Ethics Committee in Animal Experimentation of São Paulo State University (CEUA/UNESP, protocol no. 1243-2017), and in accordance with the ethical principles set forth by the National Council of Animal Experimentation (CONCEA).

\section{Consent for publication}

Not applicable

\section{Competing interests}

The authors declare that they have no competing interests. 


\section{References}

1. Campbell WW. Evaluation and management of peripheral nerve injury. Clin. Neurophysiol. 2008;119:1951-65.

2. Forterre F, Tomek A, Rytz U, Brunnberg L, Jaggy A, Spreng D. latrogenic sciatic nerve injury in eighteen dogs and nine cats (1997-2006). Vet. Surg. 2007;36:464-71.

3. Van Soens I, Struys MM, Polis IE, Bhatti SF, Van Meervenne SA, Martlé VA, et al. Magnetic stimulation of the radial nerve in dogs and cats with brachial plexus trauma: A report of 53 cases. Vet. J. 2009;182:108-13.

4. Steinberg HS. Brachial plexus injuries and dysfunctions. Vet. Clin. North Am. Small Anim. Pract. 1988; 18:565-580.

5. Asplund M, Nilsson M, Jacobsson A, Von Holst H. Incidence of traumatic peripheral nerve injuries and amputations in Sweden between 1998 and 2006. Neuroepidemiology. 2009;32:217-28.

6. Kol A, Arzi B, Athanasiou KA, Farmer DL, Nolta JA, Rebhun RB, Chen X, Griffiths LG, Verstraete FJ, Murphy CJ, Borjesson DL. Companion animals: Translational scientist's new best friends. Sci. Transl. Med. 2015;7:308ps21.

7. Terzis J, Faibisoff B, Williams HB. The nerve gap: Suture under tension vs. graft. Plast. Reconstr. Surg. 1975;56:166-70.

8. Griffin JW, Hogan M V, Chhabra AB, Deal DN. Peripheral Nerve Repair and Reconstruction. J. Bone Jt. Surg. 2013;95:2144-51.

9. Scheib J, Höke A. Advances in peripheral nerve regeneration. Nat. Rev. Neurol. 2013;9:668-76.

10. Ray WZ, Mackinnon SE. Management of nerve gaps: Autografts, allografts, nerve transfers, and endto-side neurorrhaphy. Exp. Neurol. 2010;223:77-85.

11. Nectow AR, Marra KG, Kaplan DL. Biomaterials for the Development of Peripheral Nerve Guidance Conduits. Tissue Eng. Part B Rev. 2012;18:40-50.

12. Dodla MC, Alvarado-Velez M, Mukhatyar VJ, Bellamkonda R V. Peripheral Nerve Regeneration. Princ. Regen. Med. 2019;1223-36.

13. Konofaos P, Ver Halen JP. Nerve repair by means of tubulization: past, present, future. J. Reconstr. Microsurg. 2013;29:149-64.

14. Wu R, Wang L, Chen F, Huang Y, Shi J, Zhu X, et al. Evaluation of artificial nerve conduit and autografts in peripheral nerve repair in the rat model of sciatic nerve injury. Neurol. Res. 2016;38:461-6.

15. Waitayawinyu T, Parisi DM, Miller B, Luria S, Morton HJ, Chin SH, et al. A Comparison of Polyglycolic Acid Versus Type 1 Collagen Bioabsorbable Nerve Conduits in a Rat Model: An Alternative to Autografting. J. Hand Surg. Am. 2007;32:1521-9.

16. Saltzman EB, Villa JC, Doty SB, Feinberg JH, Lee SK, Wolfe SW. A Comparison Between Two Collagen Nerve Conduits and Nerve Autograft: A Rat Model of Motor Nerve Regeneration. J. Hand Surg. Am. 2019;44:p700.e1-700.e9. 
17. Moore AM, Kasukurthi R, Magill CK, Farhadi HF, Borschel GH, Mackinnon SE. Limitations of Conduits in Peripheral Nerve Repairs. Hand. 2009;4:180-6.

18. Pedde RD, Mirani B, Navaei A, Styan T, Wong S, Mehrali M, et al. Emerging Biofabrication Strategies for Engineering Complex Tissue Constructs. Adv. Mater. 2017;29.

19. Lundborg G. A 25-year perspective of peripheral nerve surgery: Evolving neuroscientific concepts and clinical significance. J. Hand Surg. Am. 2000;25:391-414.

20. Rajaram A, Chen XB, Schreyer DJ. Strategic design and recent fabrication techniques for bioengineered tissue scaffolds to improve peripheral nerve regeneration. Tissue Eng. - Part B Rev. 2012;18:454-67.

21. Johnson BN, Lancaster KZ, Zhen G, He J, Gupta MK, Kong YL, et al. 3D Printed Anatomical Nerve Regeneration Pathways. Adv. Funct. Mater. 2015;25:6205-17.

22. Vijayavenkataraman S, Zhang S, Thaharah S, Sriram G, Lu WF, Fuh JYH. Electrohydrodynamic Jet 3D Printed Nerve Guide Conduits (NGCs) for peripheral Nerve Injury Repair. Polymers (Basel). 2018;10:1-26.

23. Zhu W, Tringale KR, Woller SA, You S, Johnson S, Shen H, et al. Rapid continuous 3D printing of customizable peripheral nerve guidance conduits. Mater. Today. 2018;21:951-9.

24. Wang S, Cai L. Polymers for fabricating nerve conduits. Int. J. Polym. Sci. 2010;2010.

25. Biscola NP, Cartarozzi LP, Ferreira R.S. J, Barraviera B, De Oliveira ALR. Long-standing motor and sensory recovery following acute fibrin sealant based neonatal sciatic nerve repair. Neural Plast. 2016;2016.

26. Frattini F, Pereira Lopes FR, Almeida FM, Rodrigues RF, Boldrini LC, Tomaz MA, et al. Mesenchymal stem cells in a polycaprolactone conduit promote sciatic nerve regeneration and sensory neuron survival after nerve injury. Tissue Eng. Part A. 2012;18:2030-9.

27. Carrier-Ruiz A, Evaristo-Mendonça F, Mendez-Otero R, Ribeiro-Resende VT. Biological behavior of mesenchymal stem cells on poly- $\varepsilon$-caprolactone filaments and a strategy for tissue engineering of segments of the peripheral nerves. Stem Cell Res. Ther. Stem Cell Research \& Therapy; 2015;6:128.

28. Yu W, Zhao W, Zhu C, Zhang X, Ye D, Zhang W, et al. Sciatic nerve regeneration in rats by a promising electrospun collagen/poly( $\varepsilon$-caprolactone) nerve conduit with tailored degradation rate. BMC Neurosci. 2011;12:68.

29. Hood B, Levene HB, Levi AD. Transplantation of autologous Schwann cells for the repair of segmental peripheral nerve defects. Neurosurg. Focus. 2009;26:E4.

30. Caseiro AR, Pereira T, Ivanova G, Luís AL, Maurício AC. Neuromuscular Regeneration: Perspective on the Application of Mesenchymal Stem Cells and Their Secretion Products. Stem Cells Int. 2016;2016:1-16.

31. Kisiel a H, McDuffee L a, Masaoud E, Bailey TR, Esparza Gonzalez BP, Nino-Fong R. Isolation, characterization, and in vitro proliferation of canine mesenchymal stem cells derived from bone marrow, adipose tissue, muscle, and periosteum. Am. J. Vet. Res. 2012;73:1305-17. 
32. Martinello T, Bronzini I, Maccatrozzo L, Mollo a., Sampaolesi M, Mascarello F, et al. Canine adiposederived-mesenchymal stem cells do not lose stem features after a long-term cryopreservation. Res. Vet. Sci. 2011;91:18-24.

33. Vieira NM, Brandalise V, Zucconi E, Secco M, Strauss BE, Zatz M. Isolation, Characterization, and Differentiation Potential of Canine Adipose-Derived Stem Cells. Cell Transplant. 2010;19:279-89.

34. Tomita K, Madura T, Mantovani C, Terenghi G. Differentiated adipose-derived stem cells promote myelination and enhance functional recovery in a rat model of chronic denervation. J. Neurosci. Res. 2012;90:1392-402.

35. Lopatina T, Kalinina N, Karagyaur M, Stambolsky D, Rubina K, Revischin A, et al. Adipose-derived stem cells stimulate regeneration of peripheral nerves: BDNF secreted by these cells promotes nerve healing and axon growth De Novo. PLoS One. 2011;6.

36. Uccelli A, Moretta L, Pistoia V. Mesenchymal stem cells in health and disease. Nat. Rev. Immunol. 2008;8:726-36.

37. Noronha NDC, Mizukami A, Caliári-Oliveira C, Cominal JG, Rocha JLM, Covas DT, et al. Correction to: Priming approaches to improve the efficacy of mesenchymal stromal cell-based therapies. Stem Cell Res. Ther. Stem Cell Research \& Therapy; 2019;10:132.

38. Araújo MR, Kyrylenko S, Spejo AB, Castro MV, Ferreira Junior RS, Barraviera B, et al. Transgenic human embryonic stem cells overexpressing FGF2 stimulate neuroprotection following spinal cord ventral root avulsion. Exp. Neurol. 2017;294:45-57.

39. Ferreira RS, De Barros LC, Abbade LPF, Barraviera SRCS, Silvares MRC, De Pontes LG, Dos Santos LD, Barraviera B. Heterologous fibrin sealant derived from snake venom: from bench to bedside - an overview. J. Venom. Anim. Toxins Incl. Trop. Dis. 2017;23:1.

40. Mozafari R, Kyrylenko S, Castro MV, Ferreira RS, Barraviera B, Oliveira ALR. Combination of heterologous fibrin sealant and bioengineered human embryonic stem cells to improve regeneration following autogenous sciatic nerve grafting repair. J. Venom. Anim. Toxins Incl. Trop. Dis. 2018; 24:1.

41. Rosso MPO, Campos LMG, Ferreira Jr RS, Barraviera B, Buchaim RL. Unique heterologous fibrin biopolymer with hemostatic, adhesive, sealant, scaffold and drug delivery properties: a systematic review. J. Venom. Anim. Toxins Incl. Trop. Dis. 2019;25:1.

42. De Castro MV, Barbizan R, Ferreira RS, Barraviera B, De Oliveira ALR. Direct Spinal Ventral Root Repair following Avulsion: Effectiveness of a New Heterologous Fibrin Sealant on Motoneuron Survival and Regeneration. Neural Plast. 2016;2016.

43. Barbizan R, Castro M V., Rodrigues AC, Barraviera B, Ferreira RS, Oliveira ALR. Motor Recovery and Synaptic Preservation after Ventral Root Avulsion and Repair with a Fibrin Sealant Derived from Snake Venom. PLoS One. 2013;8:1-12.

44. Biscola NP, Cartarozzi LP, Ulian-Benitez S, Barbizan R, Castro MV, Spejo AB, et al. Multiple uses of fibrin sealant for nervous system treatment following injury and disease. J. Venom. Anim. Toxins Incl. Trop. Dis. 2017;23:1-11. 
45. Kempe PRG, Chiarotto GB, Barraviera B, Ferreira Jr RS, Oliveira ALR. Neuroprotection and immunomodulation by dimethyl fumarate and a heterologous fibrin biopolymer after ventral root avulsion and reimplantation. J. Venom. Anim. Toxins Incl. Trop. Dis. 2020;26:1.

46. Leite APS, Pinto CG, Tibúrcio FC, Sartori AA, Rodrigues AC, Barraviera B, Ferreira, RS, Filadelpho AL, Matheus SMM. Heterologous fibrin sealant potentiates axonal regeneration after peripheral nerve injury with reduction in the number of suture points. Injury. 2019;50:834-847.

47. Araña M, Mazo M, Aranda P, Pelacho B, Prosper F. Adipose Tissue-Derived Mesenchymal Stem Cells: Isolation, Expansion, and Characterization. In: Kao RL, editor. Cellular Cardiomyoplasty: Methods and Protocols, Methods in Molecular Biology. Kao RL, editor. Totowa, NJ: Humana Press; 2013. p.47-61.

48. Ivanovska A, Grolli S, Borghetti P, Ravanetti F, Conti V, De Angelis E, et al. Immunophenotypical characterization of canine mesenchymal stem cells from perivisceral and subcutaneous adipose tissue by a species-specific panel of antibodies. Res. Vet. Sci. 2017;114:51-8.

49. Russell KA, Chow NHC, Dukoff D, Gibson TWG, LaMarre J, Betts DH, et al. Characterization and Immunomodulatory Effects of Canine Adipose Tissue- and Bone Marrow-Derived Mesenchymal Stromal Cells. Kerkis I, editor. PLoS One. 2016;11:e0167442.

50. Amorim RM, Clark KC, Walker NJ, Kumar P, Herout K, Borjesson DL, et al. Placenta-derived multipotent mesenchymal stromal cells: a promising potential cell-based therapy for canine inflammatory brain disease. Stem Cell Res. 2020;11:304.

51. Livak KJ, Schmittgen TD. Analysis of relative gene expression data using real-time quantitative PCR and the 2- $\triangle \Delta C T$ method. Methods. 2001; 25:402-8.

52. Lixandrão Filho AL, Noritomi PY, Da Silva JVL, Inforçatti Neto P, Cheung PYC, Colangelo N, et al. Construction and adaptation of an open source rapid prototyping machine for biomedical research purposes - A multinational collaborative development. Innov. Dev. Des. Manuf. - Adv. Res. Virtual Rapid Prototyp. 2010;2959:469-73.

53. Inforçatti Neto P, Lixandrão Filho AL, Pereira FDAS, Silva JVL, Silveira ZC. Thermoplastic filament extruder head for desktop Additive Manufacturing machines; In: Bartolo, PJS. Editor. Innovative Developments in Virtual and Physical Prototyping. London: Taylor \& Francis group. 2011. p. 635-638.

54. Maurmann N, Pereira DP, Burguez D, Pereira FDADS, Neto PI, Rezende RA, et al. Mesenchymal stem cells cultivated on scaffolds formed by 3D printed PCL matrices, coated with PLGA electrospun nanofibers for use in tissue engineering. Biomed. Phys. Eng. Express. 2017;3:45005.

55. Yannas I V., Zhang M, Spilker MH. Standardized criterion to analyze and directly compare various materials and models for peripheral nerve regeneration. J. Biomater. Sci. Polym. Ed. 2007;18:94366.

56. Gasparotto VPO, Landim-Alvarenga FC, Oliveira ALR, Simões GF, Lima-Neto JF, Barraviera B, et al. A new fibrin sealant as a three-dimensional scaffold candidate for mesenchymal stem cells. Stem Cell Res. Ther. 2014;5:78.

57. Bain JR, Mackinnon SE, Hunter DA. Functional Evaluation of Complete Sciatic, Peroneal, and Posterior Tibial Nerve Lesions in the Rat. Plast. Reconstr. Surg. 1989;83:129-36. 
58. Valero-Cabré A, Navarro X. H reflex restitution and facilitation after different types of peripheral nerve injury and repair. Brain Res. 2001;919:302-12.

59. Navarro X, Verdú E, Butí M. Comparison of Regenerative and Reinnervating Capabilities of Different Functional Types of Nerve Fibers. Exp. Neurol. 1994;129:217-24.

60. Mayhew TM, Sharma a K. Sampling schemes for estimating nerve fibre size. II. Methods for unifascicular nerve trunks. J. Anat. 1984;139:59-66.

61. Oliveira ALR, Thams S, Lidman O, Piehl F, Hokfelt T, Karre K, et al. From The Cover: A role for MHC class I molecules in synaptic plasticity and regeneration of neurons after axotomy. Proc. Natl. Acad. Sci. 2004;101:17843-8.

62. Cartarozzi LP, Perez M, Kirchhoff F, Oliveira ALR de. Role of MHC-I Expression on Spinal Motoneuron Survival and Glial Reactions Following Ventral Root Crush in Mice. Cells. 2019;8:483.

63. Sanchez DNR, Bertanha M, Fernandes TD, de Lima Resende LA, Deffune E, Amorim RM. Effects of Canine and Murine Mesenchymal Stromal Cell Transplantation on Peripheral Nerve Regeneration. Int. J. Stem Cells. 2017;10:83-92.

64. Tajdaran K, Chan K, Gordon T, Borschel GH. Matrices, scaffolds, and carriers for protein and molecule delivery in peripheral nerve regeneration. Exp. Neurol. 2019;319:1-16.

65. Fadia NB, Bliley JM, DiBernardo GA, Crammond DJ, Schilling BK, Sivak WN, et al. Long-gap peripheral nerve repair through sustained release of a neurotrophic factor in nonhuman primates. Sci. Transl. Med. 2020;12:eaav7753.

66. Klimaschewski L, Hausott B, Angelov DN. The pros and cons of growth factors and cytokines in peripheral axon regeneration. Int. Rev. Neurobiol. 2013;108:137-171.

67. Brohlin M, Kingham PJ, Novikova LN, Novikov LN, Wiberg M. Aging effect on neurotrophic activity of human mesenchymal stem cells. PLoS One. 2012;7:e45052.

68. Kingham PJ, Kolar MK, Novikova LN, Novikov LN, Wiberg M. Stimulating the neurotrophic and angiogenic properties of human adipose-derived stem cells enhances nerve repair. Stem Cells Dev. 2014;23:741-54.

69. Gu Y, Wang J, Ding F, Hu N, Wang Y, Gu X. Neurotrophic actions of bone marrow stromal cells on primary culture of dorsal root ganglion tissues and neurons. J. Mol. Neurosci. 2010; 40(3):332-41.

70. Takemura Y, Imai S, Kojima H, Katagi M, Yamakawa I, Kasahara T, et al. Brain-Derived Neurotrophic Factor from Bone Marrow-Derived Cells Promotes Post-Injury Repair of Peripheral Nerve. PLoS One. 2012;7:4-11.

71. Kinnaird T, Stabile E, Burnett MS, Lee CW, Barr S, Fuchs S, et al. Marrow-Derived Stromal Cells Express Genes Encoding a Broad Spectrum of Arteriogenic Cytokines and Promote In vitro and In vivo Arteriogenesis Through Paracrine Mechanisms. Circ. Res. 2004; 94(5):678-85.

72. Nakamura T, Mizuno S. The discovery of Hepatocyte Growth Factor (HGF) and its significance for cell biology, life sciences and clinical medicine. Proc. Japan Acad. Ser. B Phys. Biol. Sci. 2010; 86(6):588-610. 
73. Eleuteri S, Fierabracci A. Insights into the Secretome of Mesenchymal Stem Cells and Its Potential Applications. Int. J. Mol. Sci. 2019;20:4597.

74. Ribeiro TB, Duarte ASS, Longhini ALF, Pradella F, Farias AS, Luzo ACM, et al. Neuroprotection and immunomodulation by xenografted human mesenchymal stem cells following spinal cord ventral root avulsion. Sci. Rep. 2015;5:1-12.

75. Stoll G, Müller HW. Nerve injury, axonal degeneration and neural regeneration: basic insights. Brain Pathol. 1999;9:313-25.

76. Bauer S, Kerr BJ, Patterson PH. The neuropoietic cytokine family in development, plasticity, disease and injury. Nat. Rev. Neurosci. 2007; 8(3):221-32.

77. DeFrancesco-Lisowitz A, Lindborg JA, Niemi JP, Zigmond RE. The neuroimmunology of degeneration and regeneration in the peripheral nervous system. Neuroscience. 2015;302:174-203.

78. Gillen C, Jander S, Stoll G. Sequential expression of mRNA for proinflammatory cytokines and interleukin-10 in the rat peripheral nervous system: Comparison between immune-mediated demyelination and Wallerian degeneration. J. Neurosci. Res. 1998; 51:489-96.

79. Dubový P, Klusáková I, Hradilová Svíženská I. Inflammatory profiling of Schwann cells in contact with growing axons distal to nerve injury. Biomed Res. Int. 2014; 2014:691041.

80. Allodi I, Udina E, Navarro X. Specificity of peripheral nerve regeneration: Interactions at the axon level. Prog. Neurobiol. 2012;98:16-37.

81. Wang A, Brown EG, Lankford L, Keller BA, Pivetti CD, Sitkin NA, et al. Placental Mesenchymal Stromal Cells Rescue Ambulation in Ovine Myelomeningocele. Stem Cells Transl. Med. 2015;4:659-69.

82. Ko KR, Lee J, Lee D, Nho B, Kim S. Hepatocyte Growth Factor (HGF) Promotes Peripheral Nerve Regeneration by Activating Repair Schwann Cells. Sci. Rep. 2018; 29;8:8316.

83. Rotshenker $\mathrm{S}$. Wallerian degeneration: The innate-immune response to traumatic nerve injury. J. Neuroinflammation. 2011; 8:109.

84. Xiao S, Huang G, Wei Z, Nie K, Liu Z, Deng C, et al. IL-10 Gene-modified human amniotic mesenchymal stem cells augment regenerative wound healing by multiple synergistic effects. Stem Cells Int. 2019; 2019:9158016.

85. English K, Barry FP, Field-Corbett CP, Mahon BP. IFN-y and TNF-a differentially regulate immunomodulation by murine mesenchymal stem cells. Immunol. Lett. 2007; 110:91-100.

86. De Witte SFH, Franquesa M, Baan CC, Hoogduijn MJ. Toward development of imesenchymal stem cells for immunomodulatory therapy. Front. Immunol. 2016; 6:648.

87. Reid AJ, de Luca AC, Faroni A, Downes S, Sun M, Terenghi G, et al. Long term peripheral nerve regeneration using a novel PCL nerve conduit. Neurosci. Lett. 2013;544:125-30.

88. Lee SJ, Zhu W, Heyburn L, Nowicki M, Harris B, Zhang LG. Development of novel 3-D printed scaffolds with core-shell nanoparticles for nerve regeneration. IEEE Trans. Biomed. Eng. 2017;64:408-18. 
89. Cartarozzi LP, Spejo AB, Ferreira RS, Barraviera B, Duek E, Carvalho JL, et al. Mesenchymal stem cells engrafted in a fibrin scaffold stimulate Schwann cell reactivity and axonal regeneration following sciatic nerve tubulization. Brain Res. Bull. 2015;112:14-24.

90. Oliveira JT, Almeida FM, Biancalana A, Baptista AF, Tomaz MA, Melo PA, et al. Mesenchymal stem cells in a polycaprolactone conduit enhance median-nerve regeneration, prevent decrease of creatine phosphokinase levels in muscle, and improve functional recovery in mice. Neuroscience. 2010;170:1295-303.

91. Dai LG, Huang GS, Hsu SH. Sciatic nerve regeneration by cocultured schwann cells and stem cells on microporous nerve conduits. Cell Transplant. 2013;22:2029-39.

92. Hsieh SC, Chang CJ, Cheng WT, Tseng TC, Hsu SH. Effect of an epineurial-like biohybrid nerve conduit on nerve regeneration. Cell Transplant. 2016;25:559-74.

93. Liu G, Cheng Y, Guo S, Feng Y, Li Q, Jia H, et al. Transplantation of adipose-derived stem cells for peripheral nerve repair. Int. J. Mol. Med. 2011; 28:565-72.

94. Boyd JG, Gordon T. Neurotrophic factors and their receptors in axonal regeneration and functional recovery after peripheral nerve injury. Mol. Neurobiol. 2003;27:277-324.

95. Rodrigues Hell RC, Silva Costa MM, Goes AM, Oliveira ALR. Local injection of BDNF producing mesenchymal stem cells increases neuronal survival and synaptic stability following ventral root avulsion. Neurobiol. Dis. 2009;33:290-300.

96. Cosgaya JM, Chan JR, Shooter EM. The neurotrophin receptor p75NTR as a positive modulator of myelination. Science. 2002; 298:1245-8.

97. Wang J, Ding F, Gu Y, Liu J, Gu X. Bone marrow mesenchymal stem cells promote cell proliferation and neurotrophic function of Schwann cells in vitro and in vivo. Brain Res. 2009;1262:7-15.

98. Frattini F, Pereira Lopes FR, Almeida FM, Rodrigues RF, Boldrini LC, Tomaz MA, et al. Mesenchymal Stem Cells in a Polycaprolactone Conduit Promote Sciatic Nerve Regeneration and Sensory Neuron Survival after Nerve Injury. Tissue Eng. Part A. 2012;18:2030-9.

99. Spejo AB, Oliveira ALR. Synaptic rearrangement following axonal injury: Old and new players. Neuropharmacology. 2015;96:113-23.

100. Spejo AB, Chiarotto GB, Ferreira ADF, Gomes DA, Ferreira RS, Barraviera B, et al. Neuroprotection and immunomodulation following intraspinal axotomy of motoneurons by treatment with adult mesenchymal stem cells. J. Neuroinflammation. 2018;15:1-18.

101. Park WB, Kim SY, Lee SH, Kim HW, Park JS, Hyun JK. The effect of mesenchymal stem cell transplantation on the recovery of bladder and hindlimb function after spinal cord contusion in rats. BMC Neurosci. 2010; 11:119.

102. Rosado IR, Carvalho PH, Alves EGL, Tagushi TM, Carvalho JL, Silva JF, et al. Immunomodulatory and neuroprotective effect of cryopreserved allogeneic mesenchymal stem cells on spinal cord injury in rats. Genet. Mol. Res. 2017; 16.

\section{Figures}



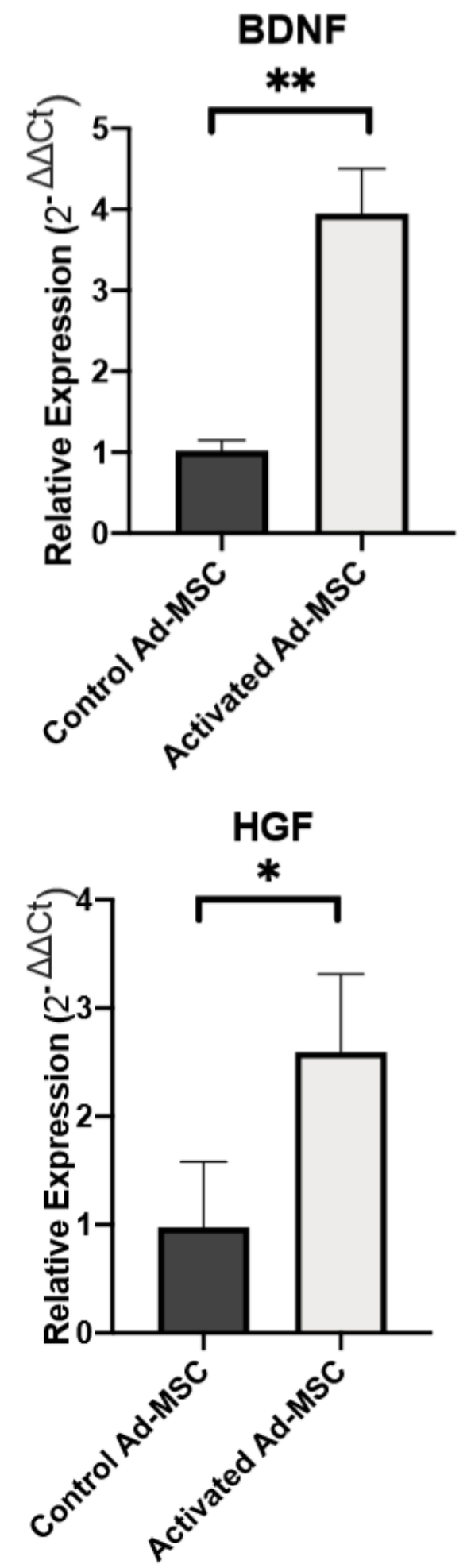
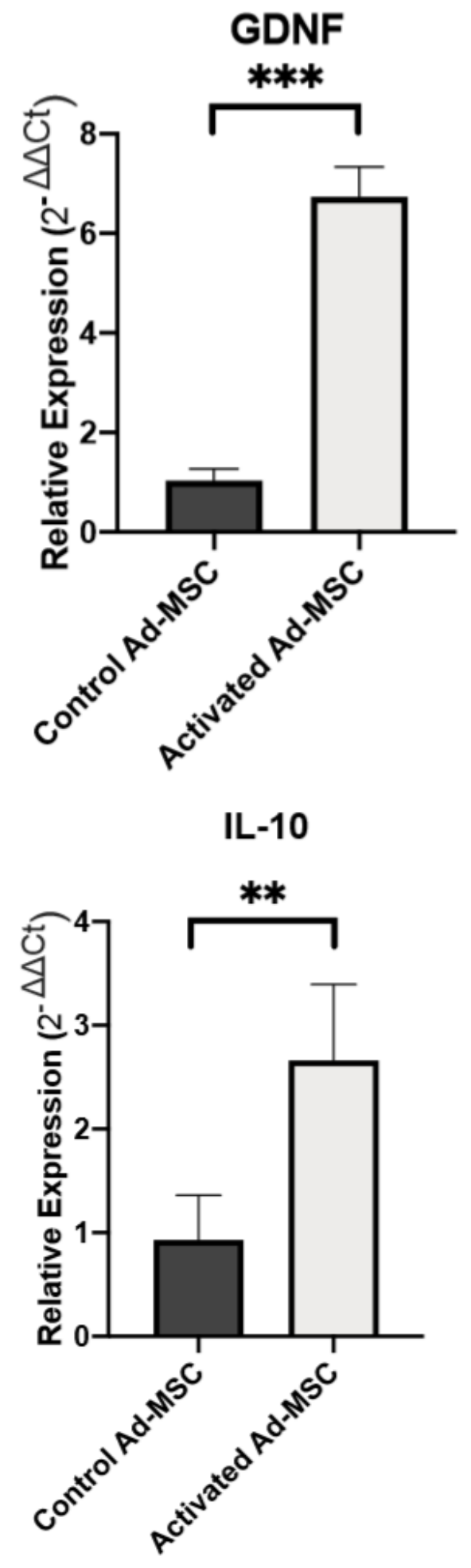

\section{Figure 1}

Relative gene expression after 96 hours following stimulation. (a) Relative expression of BDNF, (b) GDNF, (c) HGF. (d) IL-10. The samples were tested with two reference genes, glyceraldehyde-3-phosphate dehydrogenase (GAPDH) and hypoxanthine phosphoribosyl transferase (HPRT). Data are represented as mean \pm SEM. $p>0.05$. $p<0.033^{*} ; p<0.002 * * ; p<0.001^{\star \star *}$. 
A

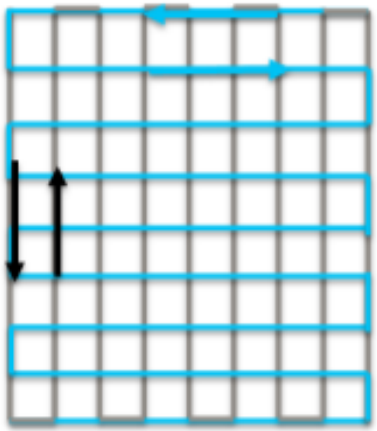

B

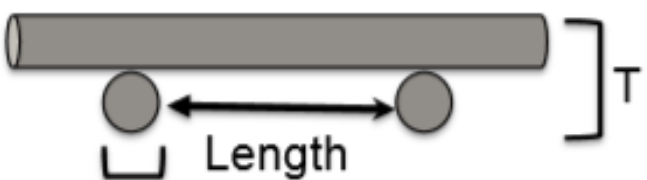

d
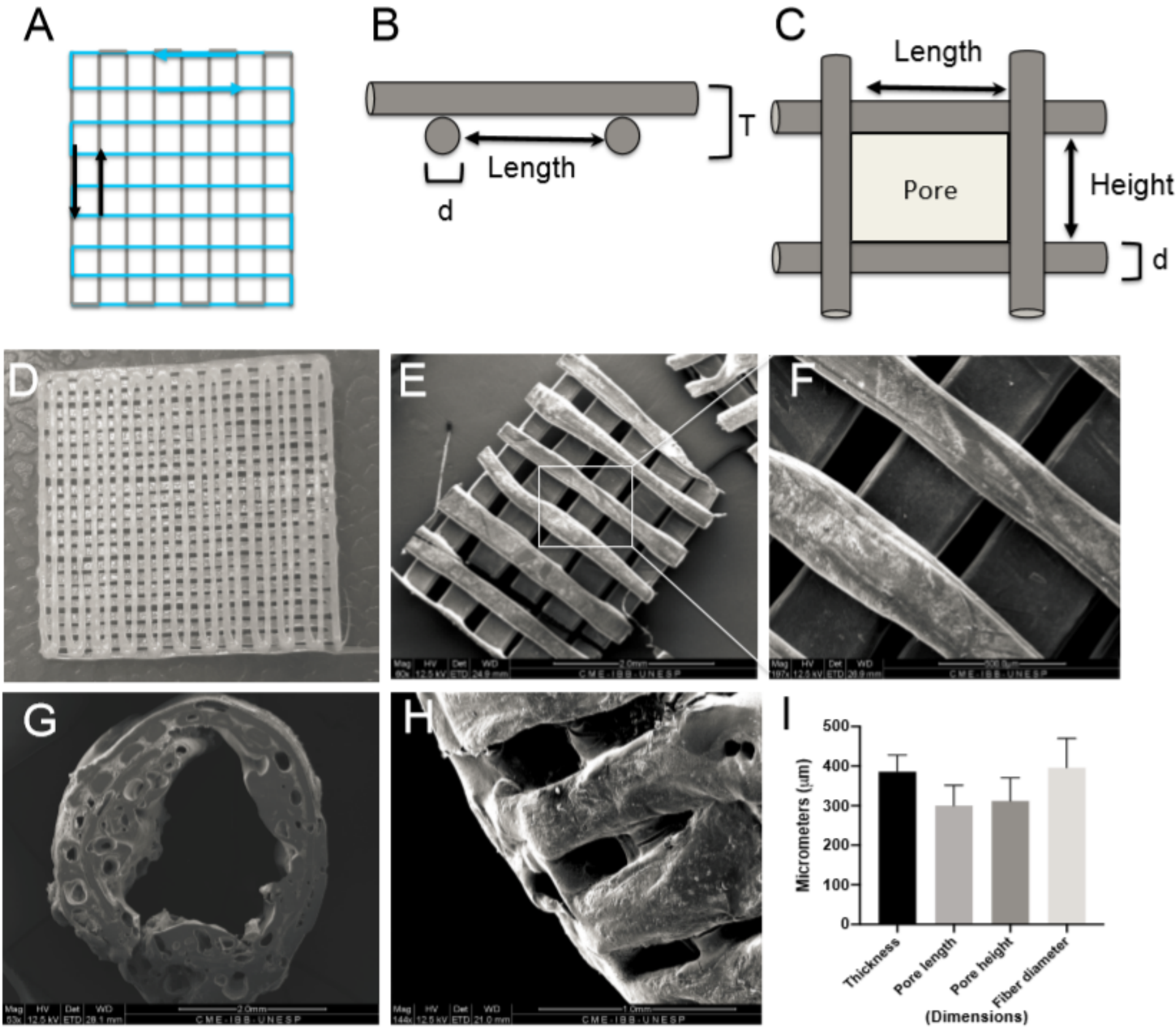

Figure 2

Geometric characterization of NGG-PCL 3D-printed membranes. (a) Height and length path of the first and second layers during 3D printing. (b) Lateral view of the two layers of PCL membranes showing diameter of filaments (d) of $396 \pm 74 \mu \mathrm{m}$. (c) Dorsal view of the PCL membranes showing pores with length of $312 \pm 58 \mu \mathrm{m}$ and height of $300 \pm 51 \mu \mathrm{m}$. (d) 3D-printed PCL membrane. (e) Internal face of PCL membrane (scale bar: $2.0 \mathrm{~mm}$ ). (f) Scanning microscopy electronic images of 3D-printed PCL membranes with different pores, filament lengths, and deposition of two layers (scale bar: $500 \mu \mathrm{m}) .(\mathrm{g})$ Cross section of the NGC after assembly (scale bar: $2.0 \mathrm{~mm}$ ). (h) External surface of the NGCs (scale bar $2.0 \mathrm{~mm}$ ). (i) Measures of geometric parameters from PCL membranes $(n=5)$. Values are represented as mean \pm SEM. 

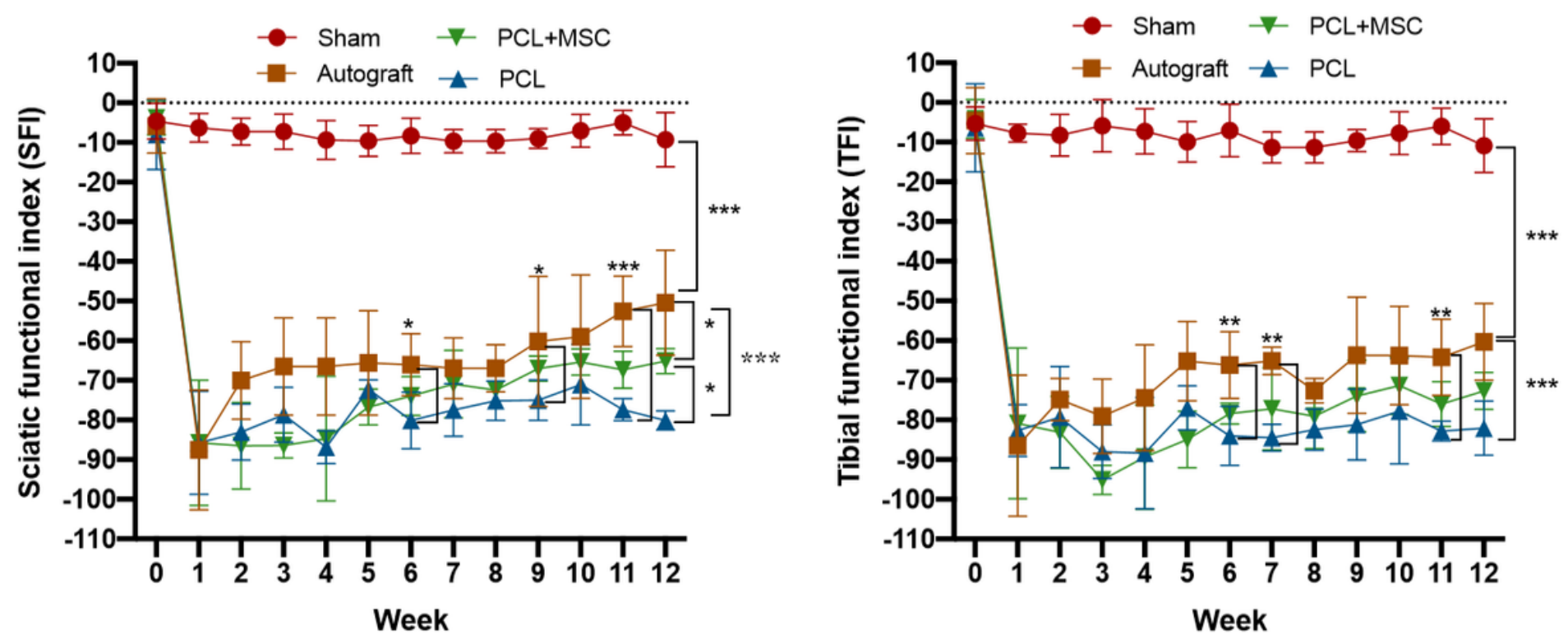

Figure 3

Analysis of locomotor functions based on sciatic nerve functionality index (SFI) and tibial functionality index (TFI) after 12 weeks in the sham, autograft, $\mathrm{PCL}$, and PCL+MSC groups. The values were obtained weekly and are represented as mean \pm SEM. $p>0.05$. $p<0.033^{*} ; p<0.002^{\star *} ; p<0.001^{\star \star \star}$. 

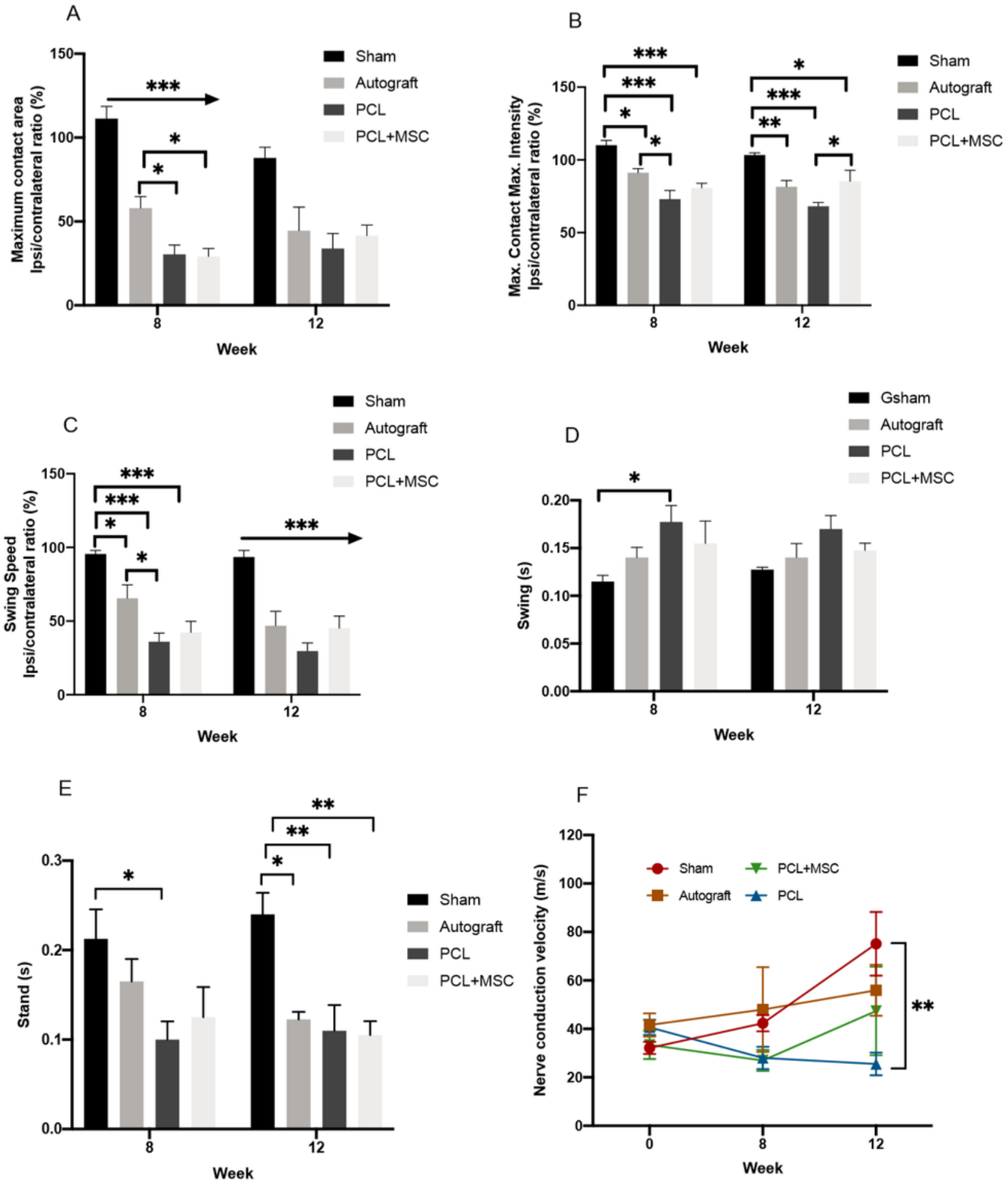

Figure 4

Gait analysis using the CatWalk platform and nerve conduction velocity (NCV) after 8 and 12 weeks in the sham, autograft, $\mathrm{PCL}$, and PCL+MSC groups. (a) Maximum contact area, (b) maximum contact intensity, (c) swing speed, (d) swing, (e) stand time, and (f) NCV (m/s). The values obtained are represented as mean \pm SEM. $p>0.05 ; p<0.033^{\star} ; p<0.002^{\star *} ; p<0.001^{\star \star \star}$. 

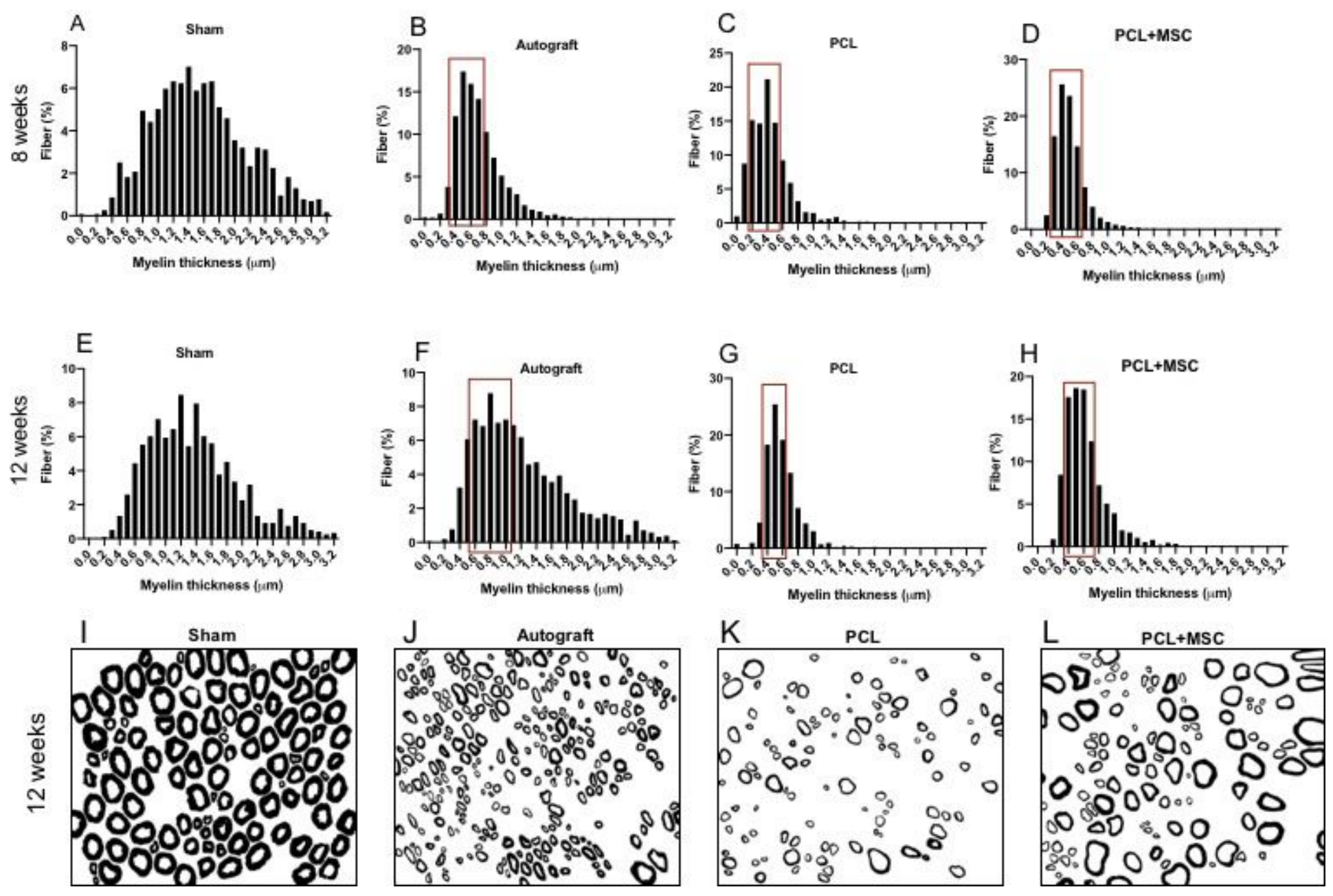

Figure 5

Frequency distribution of myelin thickness after 8 and 12 weeks following the repair of the sciatic nerve. $(a, b, c, d)$. Values were obtained after 8 weeks following the lesion in the sham, autograft, PCL, and PCL+MSC groups. $(e, f, g, h)$ Values were obtained after 12 weeks following the lesion in the sham, autograft, $\mathrm{PCL}$, and PCL+MSC groups. After 12 weeks, myelin thickness was superior in the PCL+MSC group compared with the PCL group. Red boxes highlight frequency intervals with better percentages among the autograft, $P C L$, and PCL+MSC groups. (i,j,k,l) Tendency to increase myelinated axons with larger diameters in GA and GPCL + MSCc compared to GPCL in 12 weeks was observed. Scale bar $=50$ $\mu \mathrm{m}$. 

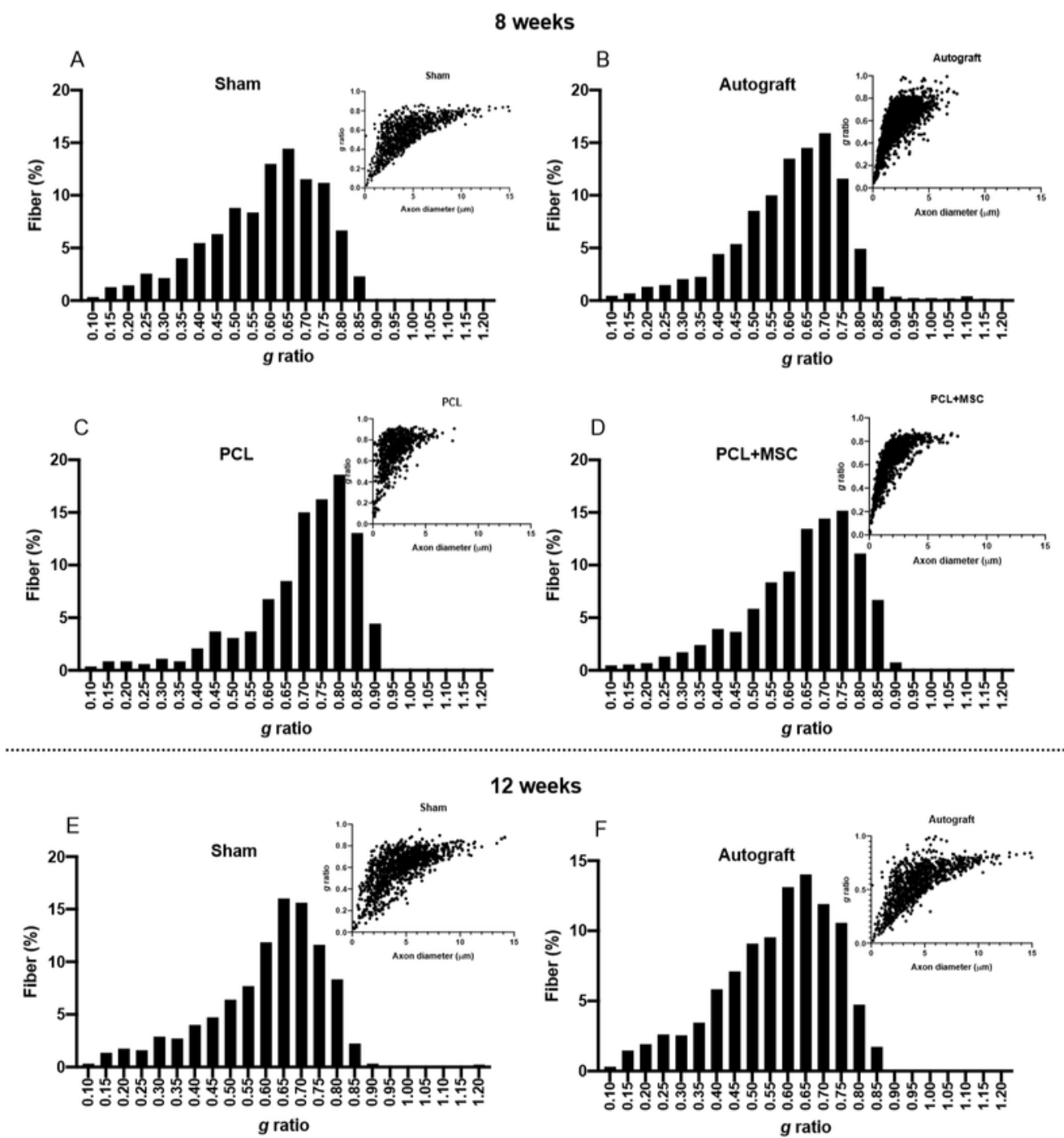

12 weeks
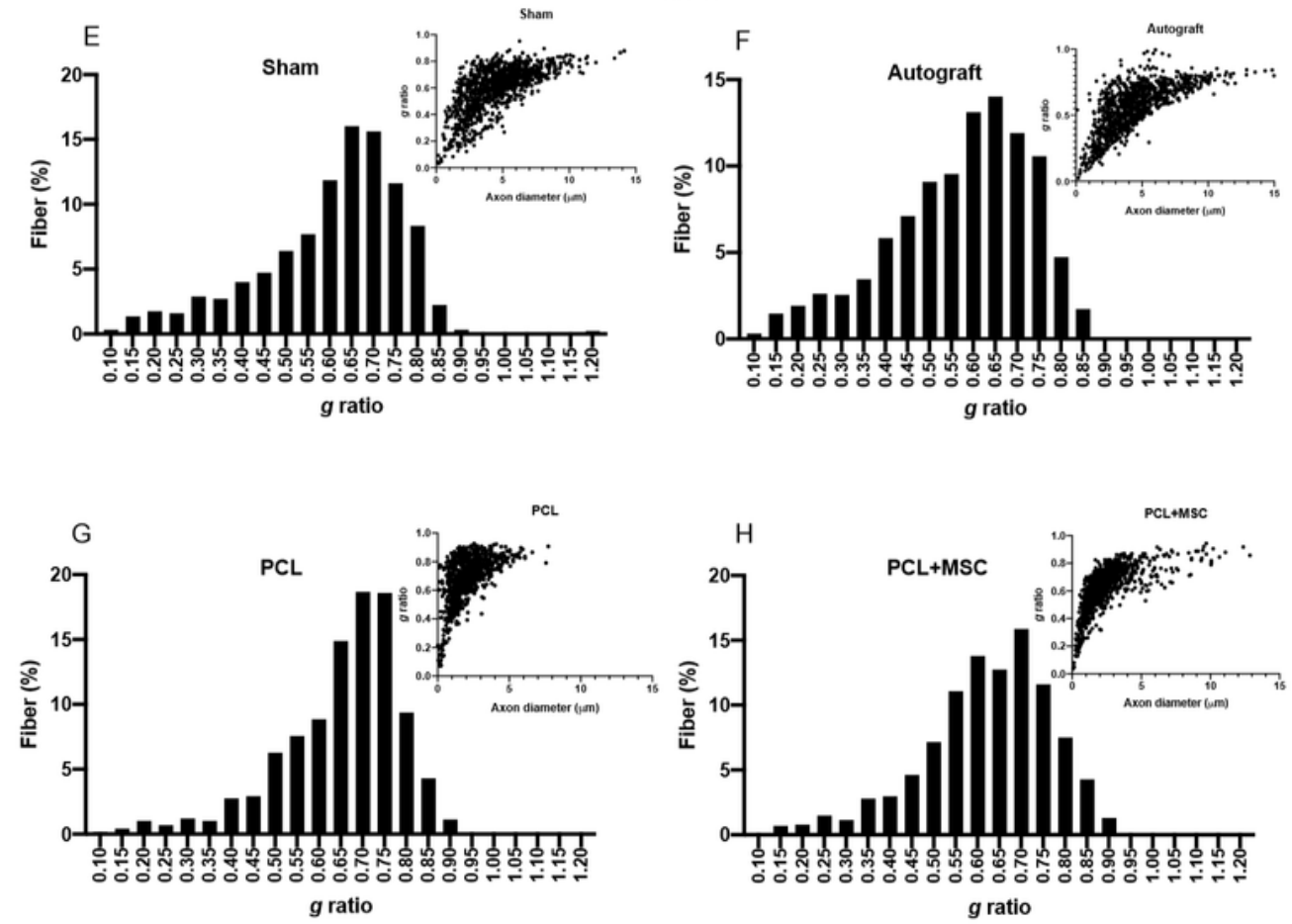

Figure 6

Frequency distribution of " $g$ " ratio and dot plot of " $g$ " ratio/axon diameter after 8 and 12 weeks. $(a, b, c, d)$ 8 weeks after the lesion in the sham, autograft, PCL, and PCL+MSC groups. (e, $f, g, h) 12$ weeks after the lesion in the sham, autograft, $\mathrm{PCL}$, and PCL+MSC groups. Note the shift towards an increase in diameter of the myelinated axon in the autograft and PCL+MSC groups when compared to the PCL group after 8 and 12 weeks. 


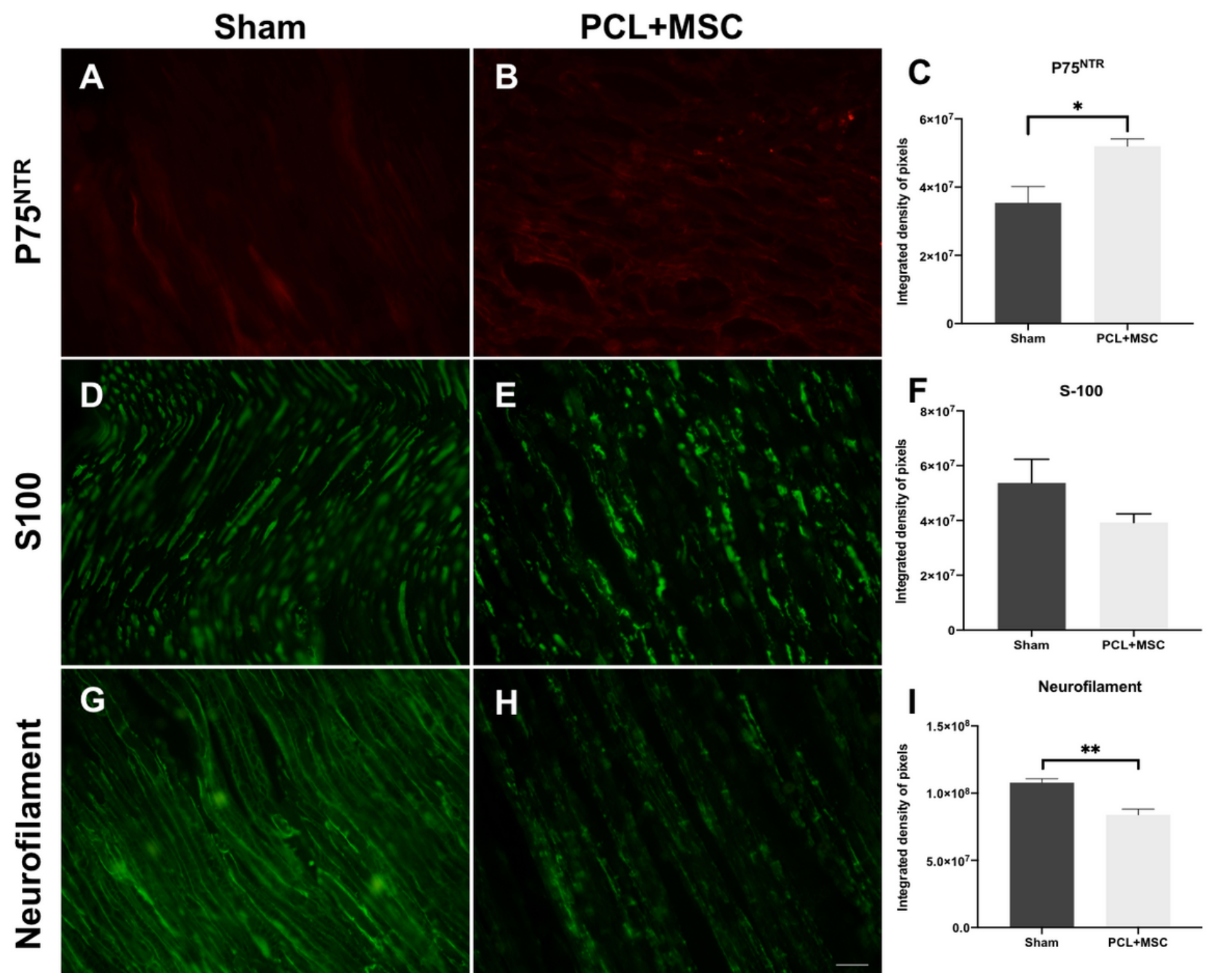

Figure 7

Quantitative analysis of the fluorescence intensity of p75NTR, S100, and neurofilament in the sciatic nerve 30 days after the experimental injury and repair. $(a, b)$ Expression of the receptor p75NTR in the proximal region of the nerve. (c) Integrated pixel density of the p75NTR receptor. (d, e) Expression of the Schwann cell marker S-100 in the proximal region of the nerve. (f) Integrated pixel density of S-100. (g, h) Expression of neurofilament in the proximal region of the nerve. (i) Integrated pixel density of neurofilament. The values of the integrated pixel density are represented as mean \pm SEM. $p>0.05$. $p<$ $0.033^{*} ; p<0.002^{\star *} ; p<0.001^{\star \star *}$. Scale bar: $50 \mu \mathrm{m}$. 


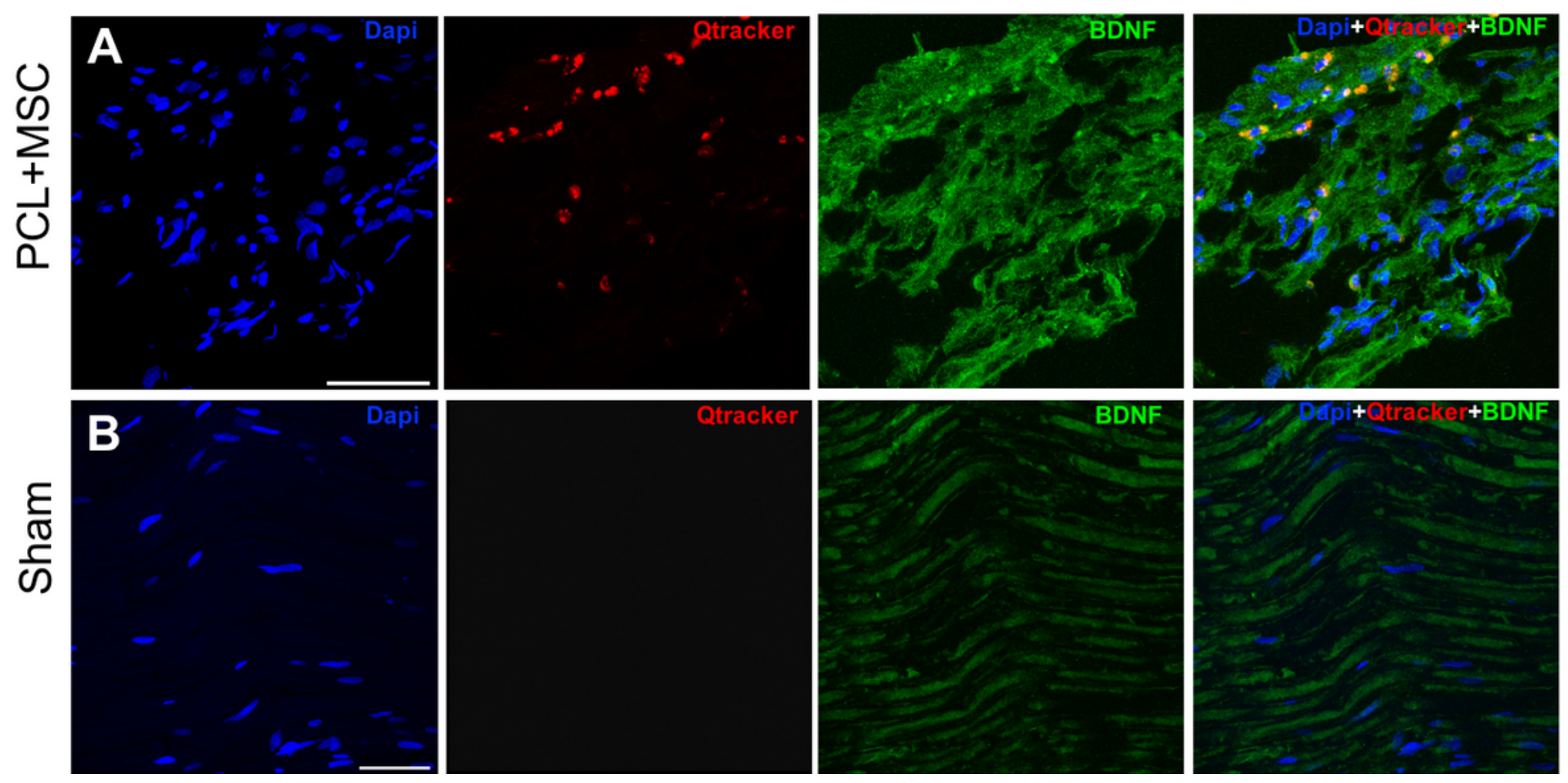

\section{Figure 8}

Qualitative analysis of BDNF immunostaining performed in the sciatic nerve 30 days after sciatic nerve injury and repair. (a) Representative images of triple labeling with anti-BDNF (green), DAPI (blue), and Qtracker ${ }^{\circledR}$ qdot655 (red) in the proximal region of the nerve. Co-localization of cells marked with qdot655 and nuclei with DAPI was observed, indicating the presence of living cells within the internal structure of the NGC. (b). BDNF immunostaining in the sham group. Cells labeled with qdot655 are absent. Scale bar: $25 \mu \mathrm{m}$.

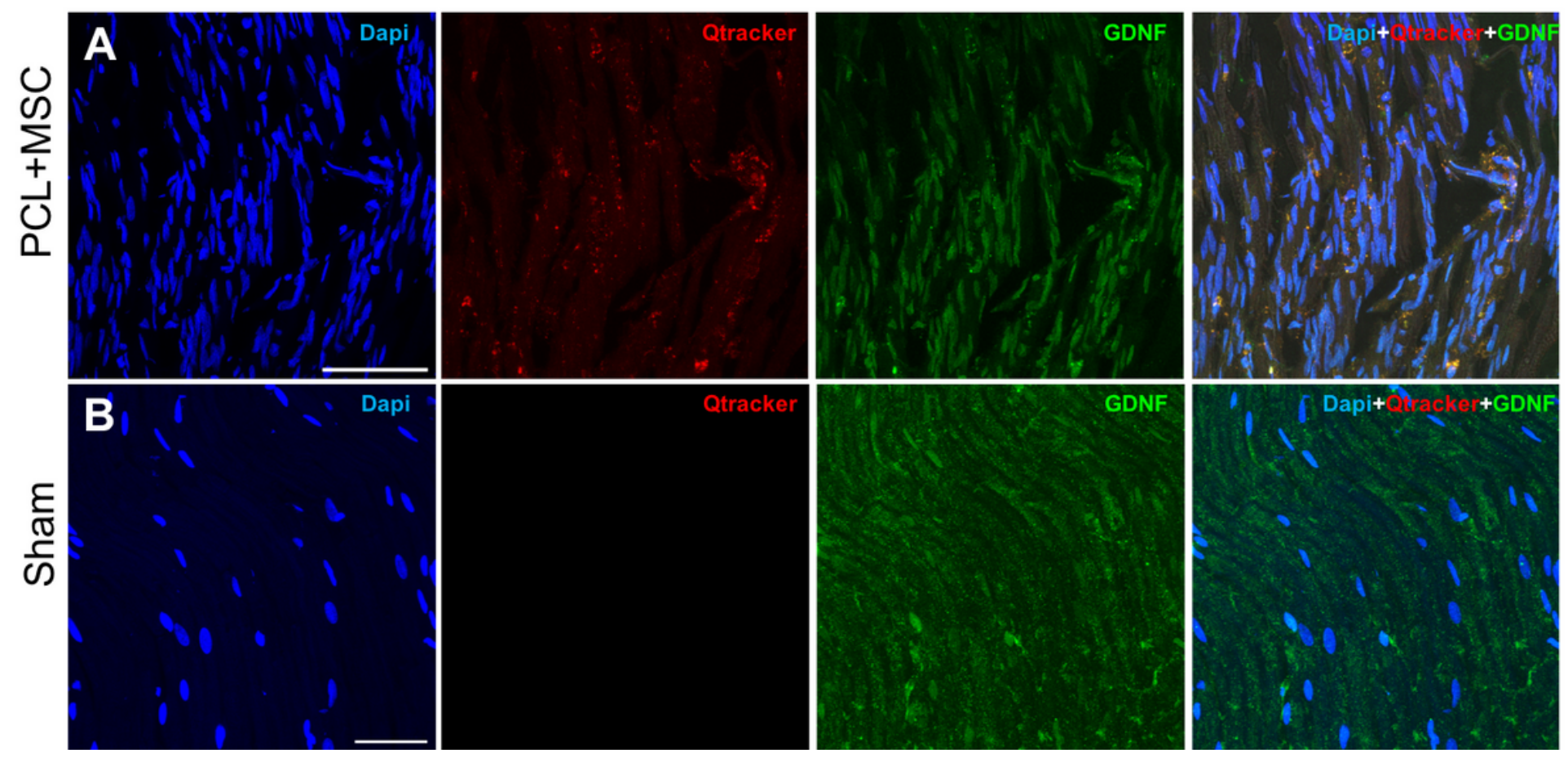

Figure 9 
Qualitative analysis of GDNF immunostaining in the sciatic nerve 30 days after sciatic nerve injury and repair. (a) Representative images of triple labeling with anti-GDNF (green), DAPI (blue), and Qtracker® qdot655 (red) in the proximal region of the nerve. It is important to note the reactivity of GDNF close to canine AdMSCs (b). GDNF in the sham group. Scale bar: $25 \mu \mathrm{m}$.
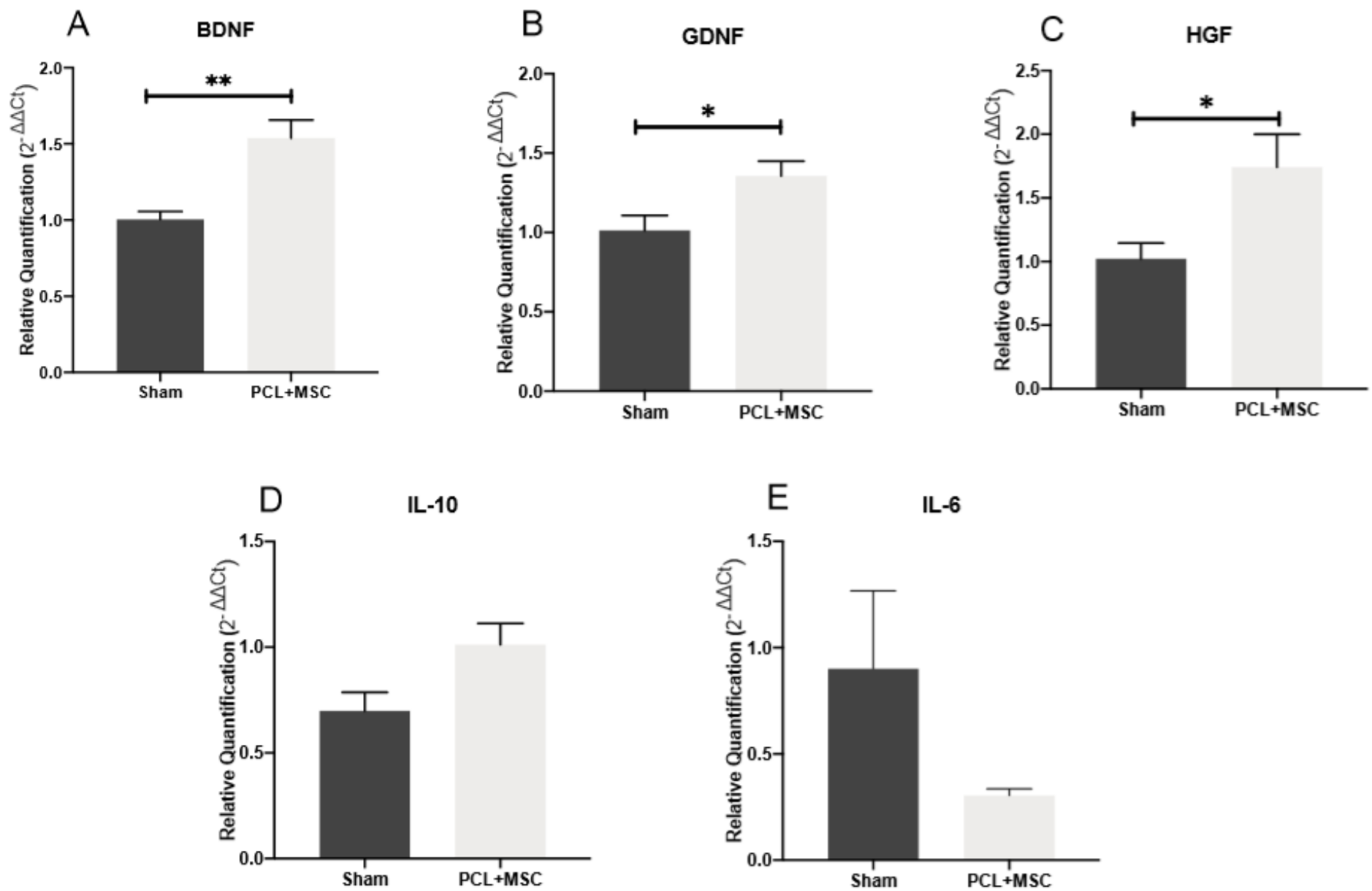

Figure 10

Gene expression in the spinal cord region ipsilateral to the lesion 30 days after nerve repair. (a-e) Relative quantification of neurotrophic factors and anti-inflammatory cytokines by qPCR in sham and PCL+MSC groups. (a) BDNF, (b) GDNF, (c) HGF, (d) IL-10, and (e) IL-6.

\section{Supplementary Files}

This is a list of supplementary files associated with this preprint. Click to download.

- AdditionalFile1.docx

- AdditionalFile2.docx

- AdditionalFile3.docx

- Figures1.pdf

- Figures2.pdf 
- Figures3.pdf

Page 37/37 